\title{
CNS Site of Action and Brainstem Circuitry Responsible for the Intravenous Effects of Nicotine on Gastric Tone
}

\author{
Manuel Ferreira Jr, ${ }^{1}$ Niaz Sahibzada, ${ }^{1,3}$ Min Shi, ${ }^{2}$ William Panico, ${ }^{1}$ Mark Niedringhaus, ${ }^{1}$ Adam Wasserman, ${ }^{1}$ \\ Kenneth J. Kellar, ${ }^{1}$ Joseph Verbalis, ${ }^{2}$ and Richard A. Gillis ${ }^{1}$ \\ ${ }^{1}$ Department of Pharmacology and '2Division of Endocrinology and Metabolism, Department of Medicine, Georgetown \\ University Medical Center, Washington, DC 20007, and ${ }^{3}$ Department of Psychology, University of the District of \\ Columbia, Washington, DC 20008
}

The purposes of our study were to determine (1) the effects of intravenous (i.v.) nicotine on gastric mechanical function of anesthetized rats, (2) the CNS site of action of nicotine to produce these effects, (3) the CNS nicotinic acetylcholine receptor (nAChR) subtype(s) responsible for mediating the i.v. effects of nicotine, and (4) the brainstem neurocircuitry engaged by i.v. nicotine for eliciting its gastric effects. This was accomplished by monitoring intragastric pressure (gastric tone) and contractility of the fundus and antrum while administering five doses of i.v. nicotine and microinjecting nicotine into specific brainstem nuclei. Additionally, c-Fos expression in the brainstem after i.v. nicotine and pharmacological agents were used as tools to identify the CNS site and circuitry and reveal the $\mathrm{nAChR}$ subtype(s) mediating the gastric effects of nicotine. Using these experimental approaches, we found the following. (1) When given intravenously in doses of $56.5,113,226,452$, and $904 \mathrm{nmol} / \mathrm{kg}$, nicotine elicited only inhibitory effects on gastric mechanical function. The most sensitive area of the stomach to nicotine was the fundus, and this effect was mediated by the vagus nerve at doses of 56.5, 113, and $226 \mathrm{nmol} /$ kg. (2) The CNS site of action and nAChR subtype responsible were glutamatergic vagal afferent nerve terminals in the medial subnucleus of the tractus solitarious (mNTS) and $\alpha 4 \beta 2$, respectively. (3) The brainstem neurocircuitry that was involved appeared to consist of a mNTS noradrenergic pathway projecting to the dorsal motor nucleus of the vagus (DMV). This pathway seems to be activated via nitriergic interneurons engaged by vagally released glutamate in the mNTS and results in $\alpha 2$ adrenergic receptor-mediated inhibition of DMV neurons projecting to the fundus and controlling gastric tone.

Key words: vagus; mNTS; DMV; c-Fos; nicotinic; gastric tone; gastric motility; intragastric pressure
Nicotine is known to produce significant effects on the gastrointestinal system (Barnett, 1927; Carlson et al., 1970a,b; Nagata et al., 1986; McDonnell and Owyang, 1989; Kohagen et al., 1996), some of which may be caused by interaction of the drug with nicotinic acetylcholine receptors (nAChRs) in the medulla oblongata (Nagata et al., 1986; Nagata and Osumi, 1991; Ferreira et al., 2000, 2001). Using the approach of microinjection of drug into specific brain areas, we reported recently that nicotine can increase gastric tone as reflected by increases in intragastric pressure (IGP) by exciting neurons in the dorsal motor nucleus of the vagus (DMV) but conversely can decrease IGP by exciting neurons in the medial nucleus of the tractus solitarius (mNTS) (Ferreira et al., 2000, 2001). On the basis of these microinjection studies and the use of pharmacological agents combined with autoradiographic and immunocytochemical studies, we have concluded that the $\alpha 7$ subtype of $\mathrm{nAChR}$ is responsible for the increase in IGP elicited from the DMV, and we suggest that the $\alpha 4 \beta 2$ subtype is responsible for the decrease in IGP elicited from the mNTS (Ferreira et al., 2000, 2001). Furthermore, local effects

Received Nov. 13, 2001; revised Jan. 4, 2002; accepted Jan. 16, 2002.

This research was supported by grants received from the National Institute of Diabetes and Digestive Diseases [Grant DK 29975 (R.A.G.), supplement to Grant DK 29975 (M.F.J.), Grant DK 57105 (R.A.G.), and Grant NS 36035 (N.S.)]. We thank Dr. Paul J Hieble (Glaxo-SmithKline Beecham Pharmacauticals, King of Prussia, PA) for the SKF 86466 used in these studies and Matthew Wester for expert technical assistance.

Correspondence should be addressed to Dr. Richard A. Gillis, Department of Pharmacology, Georgetown University Medical Center, 3900 Reservoir Road, NW, Washington, DC 20007. E-mail: GILLISR@georgetown.edu.

Copyright (C) 2002 Society for Neuroscience $0270-6474 / 02 / 222764-16 \$ 15.00 / 0$ of nicotine in the mNTS to decrease IGP required much lower amounts of nicotine compared with the doses of nicotine required to decrease blood pressure from the mNTS and to increase IGP from the DMV (Ferreira et al., 2000). These findings raised the question of what gastric tone and motility effects occur when nicotine is administered systemically and whether the effects produced are caused by nicotine exciting $\alpha 4 \beta 2$ and/or $\alpha 7 \mathrm{nAChR}$ subtypes in the mNTS or DMV, respectively.

Our findings presented in this paper indicate that only inhibitory effects of nicotine occur on gastric mechanical function when the drug is administered intravenously and that this nicotineinduced inhibition observed with "low" intravenous (i.v.) doses results from an action of the drug in the mNTS. Furthermore, our new data indicate that the $\mathrm{nAChR}$ involved in the mNTS is the $\alpha 4 \beta 2$ subtype, and the vago-vagal neuropathway mediating nicotine-induced inhibition of gastric tone is revealed.

\section{MATERIALS AND METHODS}

Animals and surgical preparation. Experiments were performed on male Sprague Dawley rats $(n=346)$ weighing 250-350 gm (Taconic, Germantown, NY) in accordance with the National Institutes of Health guidelines for the use of animals in research and with the approval of the Animal Care and Utilization Committee of Georgetown University, Washington, DC.

Before all anesthetized rat experiments, food was withheld overnight, whereas water was provided ad libitum. Animals were anesthetized with an intraperitoneal injection of a mixture $(3 \mathrm{ml} / \mathrm{kg})$ containing urethane $(800 \mathrm{mg} / \mathrm{kg})$ and $\alpha$-chloralose $(60 \mathrm{mg} / \mathrm{kg})$ dissolved in 3 $\mathrm{ml}$ of $0.9 \%$ saline. Body temperature was monitored by a rectal thermometer and maintained at $37 \pm 1^{\circ} \mathrm{C}$ with an infrared heating 
lamp. To minimize brain swelling, all animals that underwent neurosurgery were pretreated with dexamethasone $(0.8 \mathrm{mg}$, s.c.).

Rats were intubated via the trachea to maintain an open airway and to institute artificial respiration when necessary. The carotid artery and the jugular vein were also cannulated with polyethylene tubing (PE 50) for monitoring blood pressure and for systemic infusion of drugs, respectively. Blood pressure was monitored by a pressure transducer that was connected to a bridge amplifier connected to a MacLab acquisition system (ADI Instruments, Milford, MA) and then to a G3 Macintosh computer. In some animals, ligatures (with large loops) were placed around the cervical vagi to be cut or avulsed later.

To monitor gastric tone and motility, an intragastric balloon (made from the little finger of a small latex glove, connected to a polyethylene tubing, PE 160) was inserted into the stomach via the fundus and positioned toward the antrum. The balloon was inflated (by warm saline, 2-3 ml) to produce a baseline pressure of $6-15 \mathrm{mmHg}$. This tubing was also connected to a pressure transducer.

In some experiments, strain gauge force transducers (Warren Research Products, Charlestown, SC) were sutured onto specific sites of the stomach to record gastric smooth muscle activity. One strain gauge was oriented toward the circular smooth muscle of the antrum to record phasic contractile activity. Another strain gauge was oriented toward the longitudinal muscle of the fundus to record tonic contractile activity. The smooth muscle was stretched to provide a baseline gram tension of $\sim 15 \mathrm{gm}$ when the strain gauges were sutured to the stomach. The strain gauges were connected to bridge amplifiers and fed into the MacLab motherboard. Before each new experimental day, the strain gauges were calibrated using 10 and 50 gm weights.

In brain microinjection experiments, to gain access to the dorsal medulla, the animals were positioned in a stereotaxic apparatus (David Kopf, Tujunga, CA). A partial dorsal craniectomy was performed to expose the medulla. After retraction of the cerebellum, the underlying dura and subarachnoid covering were reflected. The caudal tip of the area postrema, the Calamus Scriptorius (CS), was viewed as a reference point for determining the microinjection coordinates (see below).

Brain microinjection technique and histologic verification of microinjection sites. Drugs were infused via a double-barrel pipette with an overall tip diameter of 30-60 $\mu \mathrm{m}$. All microinjections were given either unilaterally (mNTS) or bilaterally (mNTS and DMV). The dose of nicotine chosen for studying the brainstem circuitry and for establishing the dihydro- $\beta$-erythroidine (DHBE) inhibition curve was $10 \mathrm{pmol} / 60 \mathrm{nl}$ because it was a dose that worked to produce a consistent response during repeat microinjection [Note: in a previous study we learned that even a 10 -fold higher dose, i.e., 100 pmol, could elicit consistent responses during repeat microinjection provided a 15 min period was allowed between microinjections (Ferreira et al., 2000)]. Injections were administered within 5-10 sec in volumes of 60 $\mathrm{nl}$ by hand-controlled pressure. Stereotaxic coordinates for injection into the mNTS were $0.3-0.5 \mathrm{~mm}$ rostral to CS, $0.5-0.7 \mathrm{~mm}$ lateral to the midline, and $0.4-0.6 \mathrm{~mm}$ from the dorsal surface of the medulla. Coordinates for the DMV were $0.3-0.5 \mathrm{~mm}$ rostral to CS, mediolateral $0.3-0.5 \mathrm{~mm}$ from the midline, and dorsoventral $0.5-0.7 \mathrm{~mm}$ from the dorsal surface of the medulla. These coordinates are similar to those reported in our earlier studies (Ferreira et al., 2000, 2001).

At the end of each experiment, the rat was killed with an overdose of pentobarbital. The brain was removed and fixed in a mixture of $4 \%$ paraformaldehyde and $20 \%$ sucrose for at least $24 \mathrm{hr}$. It was then cut into $50-\mu \mathrm{m}$-thick coronal sections and stained with neutral red or cresyl violet. The location of microinjection sites was studied in relation to nuclear groups using the atlas of Paxinos and Watson (1998). Camera lucida drawings were performed for each experiment to document all microinjection sites. In our data presentation, we show documentary evidence for only one series of studies, namely, the studies wherein hexamethonium was microinjected into the mNTS and DMV and tested for its capacity to counteract intravenously administered nicotine on gastric function (see Fig. 4). The microinjection sites for all studies have been documented but are not presented because of space limitations. This evidence is available on request.

Vagal stimulation studies. The reason for performing these studies was to avoid erroneous interpretation of data from studies in which bilateral cervical vagotomy has been performed. That is, because bilateral cervical vagotomy abolishes a response evoked from microinjecting a drug into the DMV or mNTS, it is often interpreted to mean that the response is mediated through neurons originating in the DMV and coursing through the cervical vagus trunk to reach the stomach. However, Humphreys and colleagues (1992) have shown that this is not always the case. They provide evidence that a drug acting in the CNS can activate the sympathetic nervous system to release norepinephrine, which in turn activates $\alpha 2$ receptors on cholinergic parasympathetic neurons to inhibit acetylcholine release. To assess the contribution of a sympathetic-parasympathetic nervous system interaction at the neuroeffector junction of the stomach in nicotine-induced changes in gastric tone and motility, some animals $(n=3)$ underwent vagal stimulation [as described by Humphreys et al. (1992)]. Animals were anesthetized and prepared surgically as described above, with the cervical vagal nerves both isolated and looped with sutures. Microinjection of nicotine $(10 \mathrm{pmol} / 60 \mathrm{nl})$ into the mNTS was performed. When a robust response was elicited, both vagus nerves were cut with fine scissors. The phasic activity of the gastric baseline always $(n=3)$ ceased to exist, although the tone remained at the same level (see Fig. $7)$. Three to five millimeters of the distal cut end of one vagus nerve was placed on the stimulating electrode. Then, vagal stimulation $(5 \mathrm{~V}$, $1 \mathrm{msec}$ pulses at $5 \mathrm{~Hz}$ ) was delivered by MacLab via a bipolar platinum-iridium electrode to the peripheral cut end of the right vagus nerve. The nerve was stimulated continuously in the absence and presence of nicotine microinjected into the mNTS after sectioning of the vagi (see Fig. 7 and accompanying text).

c-Fos immunohistochemistry. Male Sprague Dawley rats, 325-425 $\mathrm{gm}$, were housed individually in a temperature-controlled room with a regular light cycle. All rats were allowed to acclimate to the facility for at least 5-7 d on standard chow and tap water before further study. Five days before study, animals were given injections of Fluorogold (Fluorochrome, Denver, CO) (0.8 mg, i.p.). Three days before study, jugular venous catheters were inserted into the right jugular vein using methods described previously (Roesch et al., 2001). On the day of study, animals were denied access to food or water from 8 A.M. Various doses of nicotine $(56.5,113,226,452$, and $904 \mathrm{nmol} / \mathrm{kg}$; see Drug administration) were dissolved in $1.0 \mathrm{ml}$ of $150 \mathrm{~mm} \mathrm{NaCl}$ and administered intravenously over $\sim 90 \mathrm{sec}$. Sixty minutes after nicotine administration, animals were anesthetized with an overdose of sodium pentobarbital $(80 \mathrm{mg} / \mathrm{kg})$. This time was chosen on the basis of previous studies which found that c-Fos immunoreactivity in hypothalamic and brainstem neurons peaks 60-90 min after stimulation (Verbalis et al., 1991; Rinaman et al., 1993). The thoracic cavity was opened, the inferior vena cava was clamped, and an 18 gauge overneedle Teflon catheter was inserted into the apex of the heart and routed to the entrance of the aorta. Five hundred units of heparin were injected into the catheter, and the right atrium was punctured to allow drainage. The animal was then perfused transcardially with $200 \mathrm{ml}$ of $0.15 \mathrm{M} \mathrm{NaCl}$ containing $2 \%$ sodium nitrite followed by $200 \mathrm{ml}$ of phosphate-buffered $4 \%$ paraformaldehyde containing $2 \%$ acrolein (Polysciences, Warrington, PA) followed by another $200 \mathrm{ml}$ of $0.15 \mathrm{M}$ $\mathrm{NaCl}$ containing $2 \%$ sodium nitrite. The brains were post-fixed overnight in phosphate-buffered $4 \%$ paraformaldehyde and then stored in $25 \%$ sucrose until sectioned. Brainstems were cut into sequential 25 $\mu \mathrm{m}$ coronal sections using a freezing-stage microtome (Jung Histoslide 2000, Deerfield, IL). The sections were collected in serially ordered sets through the rostrocaudal extent of the DMV so that each set contained a 1:6 series of hindbrain sections spaced $\sim 150 \mu \mathrm{m}$ apart. The sections were stored at $-20^{\circ} \mathrm{C}$ in tissue culture dishes containing cryoprotectant (Watson et al., 1986) until they were processed.

To ensure that the immunohistochemical analyses were representative of the entire extent of the sectioned brain area, each analysis consisted of sections that were cut $\sim 150 \mu \mathrm{m}$ apart (every sixth section). The tissue was rinsed with PBS and treated with a solution of $1 \%$ sodium borohydride for $20 \mathrm{~min}$. Next, the tissue was incubated for $48-72 \mathrm{hr}$ at $4^{\circ} \mathrm{C}$ with a rabbit-derived antibody directed against the amino terminal of c-Fos (Oncogene Sciences, Manhasset, NY; diluted 1:100,000 in PBS containing $0.4 \%$ Triton $\mathrm{X}-100$ ). Then the tissue was incubated for $1 \mathrm{hr}$ at room temperature with a biotinylated goat anti-rabbit IgG (Vector Laboratories, Burlingame, CA; diluted 1:10,000 in PBS-Triton X-100). Finally, the tissue was incubated for 1 $\mathrm{hr}$ at room temperature with avidin and a biotinylated horseradish peroxidase (Vectastain Elite ABC Kit, Vector Laboratories; $4.5 \mathrm{ml}$ of reagents A and B per milliliter, in PBS-Triton X-100). The presence of the antibody-peroxidase complex was detected by incubating with 
nickel sulfate $(25 \mathrm{mg} / \mathrm{ml}), 3,3^{\prime}$-diamino-benzidine (DAB, $0.2 \mathrm{mg} / \mathrm{ml}$ ), and hydrogen peroxide $\left(0.4 \mathrm{ml}\right.$ of $30 \% \mathrm{H}_{2} \mathrm{O}_{2}$ per milliliter $)$ in $0.175 \mathrm{M}$ sodium acetate for $10-20 \mathrm{~min}$. This reaction product was black. To identify Fluorogold-containing neurons, the same sections were double stained with an antibody directed against Fluorogold (Chemicon, Temecula, CA), diluted 1:70,000 in PBS-Triton X-100. Peroxidase was attached to the antibody as described above, and the presence of the peroxidase was detected by incubating with $\mathrm{DAB}$ and hydrogen peroxide in $0.05 \mathrm{~m}$ Tris-buffered, $\mathrm{pH} 7.2,0.15 \mathrm{~m} \mathrm{NaCl}$. This reaction product was light brown. Throughout the staining procedure, the tissue was rinsed in PBS multiple times after each incubation step. The tissue was mounted on Superfrost Plus glass slides (Fisher Scientific), air dried overnight, serially dehydrated in alcohol, cleared in Histoclear, and coverslipped with Histomount (National Diagnostics, Atlanta, GA).

Tissue slices were visualized using a Nikon Eclipse E600 microscope fitted with a linear encoder (type MSA 001-6, RSF Electronics, Inc., Rancho Cordova, CA) connected to a digital readout device (Microcode II, Boeckeler Instruments, Tucson, AZ), a video camera (DEI750, Optronics Engineering, Goleta, CA), and a microcomputer running the Bioquant software package (R\&M Biometrics, Nashville, TN). The tissue slices were visualized using $10 \times$ and $20 \times$ objective lenses, and the brain regions of interest (mNTS and DMV) were outlined using Paxinos and Watson (1998) as a guide. The numbers of total c-Fos-positive $(+)$ cells in the mNTS, and the numbers of c-Fos + and Fluorogold + immunoreactive cells in the DMV, were counted separately on each section. Using the Bioquant software package, each individual immunoreactive cell was marked during the counting process, eliminating the possibility of double counting identified cells. For each animal, all single or double-labeled neurons in each section were summed from sections that were $750 \mu \mathrm{m}$ rostral to the area postrema to $750 \mu \mathrm{m}$ caudal to the area postrema. The total number of positive cells in the area counted was then divided by the number of sections counted, and the result was expressed as c-Fos + (mNTS), or c-Fos + plus Fluorogold + (DMV), neurons per section. Statistical differences between nicotine doses were determined by one-way ANOVA followed by post hoc analysis of paired doses via the method of Student's-Newman-Keuls.

Drugs. All of the following drugs were purchased from Sigma (St. Louis, MO): $\alpha$-chloralose, bicuculline methiodide, (-)-nicotine hydrogen tartrate, N $\omega$-nitro-L-arginine methyl-ester (L-NAME), urethane, yohimbine hydrochloride, and L-arginine hydrochloride. Hexamethonium dichloride, cytisine, and DHBE hydrobromide were purchased from RBI (Natick, MA). Dexamethasone was purchased from Elkins-Sinn (Cherry Hill, NJ). SKF 86466 was a gift from Dr. Paul Heible (Glaxo-SmithKlineBeecham Pharmaceuticals, King of Prussia, PA). All drugs were dissolved in $0.9 \%$ saline. The $\mathrm{pH}$ of drug solutions used in microinjection studies was brought to 7.0-7.2. In the case of yohimbine, the $\mathrm{pH}$ was usually kept at 6.5 because of its propensity for precipitation at higher $\mathrm{pH}$. In a few experiments we were able to use yohimbine in a solution of $\mathrm{pH} 7.0-7.2$ without drug precipitating, and results were identical to those obtained when lower $\mathrm{pH}$ solutions were used. For preparing solutions with yohimbine and $\alpha$-chloralose, gentle heating was required. For i.v. studies, doses of nicotine were dissolved in $1 \mathrm{ml}$ of saline, and the $\mathrm{pH}$ was brought to 7.4. Also, i.v. nicotine was administered as $1 \mathrm{ml} / \mathrm{kg}$.

Drug administration. (-)-Nicotine hydrogen tartrate doses used in this study were calculated as the base. For i.v. administration in anesthetized rats, doses chosen were based on the published findings of Nagata and Osumi (1990), wherein they used a dose range of 75-300 $\mathrm{nmol} / \mathrm{kg}$ and found that these doses dose-dependently decreased gastric motility without producing significant changes in arterial blood pressure in the anesthetized rat. We also found that a similar dose range affected gastric tone without exerting blood pressure effects, provided that each dose was administered over $\sim 30 \mathrm{sec}$ and not as a rapid i.v. bolus over a few seconds. For the c-Fos studies performed in conscious rats, each i.v. dose of nicotine was administered over $90 \mathrm{sec}$ to avoid the deleterious behavioral effects that have been described by others (Valentine et al., 1996). Doses of nicotine (and hexamethonium) selected to microinject into brainstem nuclei were based on dose-response data from our previously published study (Ferreira et al., 2000, their Figs. 1, 8). In experiments in which hexamethonium (10 $\mathrm{mg} / \mathrm{kg}$ ) was given intravenously, animals were pretreated with $1 \mathrm{ml}$ of physiologic saline. This was done to maintain mean arterial blood pressure. In preliminary studies, animals given this dose of hexamethonium without physiologic saline died within 15 min, presumably because of severe hypotension. Cytisine was microinjected into the mNTS in the same dose range as nicotine on the basis of our earlier findings that the two agents have similar dose-response curves when tested on neurons in the medulla (DMV neurons) (Bertolino et al., 1997). A wide range of DHBE doses was tested for microinjection $(0.1-1000 \mathrm{pmol} / 60 \mathrm{nl})$. It was necessary to explore a wide dose range because although this agent has selectivity for nAChR subtypes containing a $\beta 2$ subunit, it loses its selectivity when high doses are used (Harvey and Luetje, 1996). Kynurenic acid was used for microinjection into the brainstem nuclei, and the dose was chosen on the basis of data reported by Soltis and colleagues (1991). L-NAME and L-arginine were used in microinjection studies, and the doses were chosen on the basis of findings reported by others (Panico et al., 1995; Beltran et al., 1999). Bicuculline was used in microinjection studies in a dose that was chosen on the basis of our previously published findings (Williford et al., 1981).

To assess the role of $\alpha 2$ adrenergic receptor involvement at the DMV in nicotine-evoked inhibition of gastric tone, two agents known to block this subtype of receptor were used. The first was yohimbine (Doxey et al., 1984) and the second was SKF 86466 (Hieble et al., 1986). The dose of yohimbine used for blocking $\alpha 2$ adrenergic receptors was 500 pmol and was selected on the basis of data reported by Sved and colleagues (1992), wherein they evaluated a dose range of $10-500$ pmol of yohimbine on $\alpha 2$ adrenergic responses in the NTS and found that 200 pmol was fully effective as an antagonist of this receptor. The dose of SKF 86466 was $1 \mathrm{nmol}$ and was selected on the basis of data reported by others (Ernsberger et al., 1990; Gomez et al., 1991; Sesoko et al., 1998) in which a dose range of 1-2 nmol of SKF 86466 was used to selectively block $\alpha 2$ adrenergic receptors in the ventrolateral medulla.

Data analysis and statistics. Data were analyzed using the Chart Software for data analysis made for MacLab (ADI Instruments). For analysis of IGP data, values were calculated from a 3 min segment before i.v. administration or microinjections of nicotine. The lowest points of the intragastric pressure trace obtained were averaged, and the resultant value was used as an index of gastric tone. This value did not differ significantly from other baseline values. Phasic contractions were measured more directly by extraluminal strain gauge force transducers attached to specific areas of the stomach (see below for analysis). After i.v. infusions or microinjections of drugs and vehicle, the minimum value in the IGP trace (also derived from a 3 min segment) was taken as the largest drop in gastric tone. The percentage change from baseline in IGP was then calculated. Data for IGP are reported as percentage change from baseline instead of absolute values of IGP, because baseline IGP varied among animals. It should be noted that all data that are shown to be statistically significant are significant when analyzed as both raw data and percentage change from baseline. Data appear as means (percentage change from baseline for IGP) \pm SEM.

For calculating the change in fundus activity, the same methods were used as those that were used to calculate IGP. They were used because this endpoint correlated well with changes in tone (IGP) and not with changes in contractility. Therefore, peak gram tension was used, and the raw change in grams was calculated. Data appear as means (change in grams) \pm SEM.

Antrum motility was quantified by minute motility index (MMI) based on the method of Ormsbee and Bass (1976) and later modified by Krowicki and Hornby (1993). This index takes into account both frequency and amplitude of phasic contractions in the antrum trace. Briefly, phasic contractions that had an amplitude below $1 \mathrm{gm}$ were not used for calculation of MMI, those between 1 and $2 \mathrm{gm}\left(N_{1-2 \mathrm{gm}}\right)$ were given a value of 1 , those between 2 and $4 \mathrm{gm}\left(N_{2-4 \mathrm{gm}}\right)$ were given a value of 2 , those between 4 and $8 \mathrm{gm}\left(N_{4-8 \mathrm{gm}}\right)$ were given a value of 3 , and those above $8 \mathrm{gm}\left(N_{>8 \mathrm{gm}}\right)$ were given a value of 4 . These values were added for the 5 min period to give an antrum MMI (aMMI) value: aMMI $=1\left(N_{1-2 \mathrm{gm}}\right)+2\left(N_{2-4 \mathrm{gm}}\right)+3\left(N_{4-8 \mathrm{gm}}\right)+4\left(N_{>8 \mathrm{gm}}\right)$. The antrum MMI was calculated for $5 \mathrm{~min}$ before and $5 \mathrm{~min}$ after administration of the agents and expressed as a difference between preinjection and postinjection MMI. Data appear as means (raw change in aMMI) \pm SEM.

For blood pressure calculations, the change in mean blood pressure 
Table 1. Effects of i.v. doses of nicotine on intragastric pressure, tonic contraction of the fundus, motility of the antrum, and mean arterial blood pressure

\begin{tabular}{|c|c|c|c|c|}
\hline \multirow{2}{*}{$\begin{array}{l}\text { Dose of nicotine } \\
(\mathrm{nmol} / \mathrm{kg})\end{array}$} & \multicolumn{4}{|c|}{ Effects of nicotine on } \\
\hline & IGP & Fundus & aMMI & $\mathrm{BP}$ \\
\hline 0 & $2.0 \pm 1.0 \%$ & $0.1 \pm 0.4$ & $3.2 \pm 8.0$ & $4.0 \pm 3.0$ \\
\hline 56.5 & $-6.0 \pm 2.1 \%^{a}$ & $-0.5 \pm 0.3$ & $2.1 \pm 6.2$ & $2.1 \pm 6.2$ \\
\hline 113 & $-10.0 \pm 3.2 \%{ }^{a}$ & $-0.9 \pm 0.4^{a}$ & $4.0 \pm 6.5$ & $-3.0 \pm 5.0$ \\
\hline 226 & $-12.0 \pm 2.0 \%^{a}$ & $-1.6 \pm 0.3^{a}$ & $8.0 \pm 5.1$ & $9.0 \pm 4.3$ \\
\hline 452 & $-16.0 \pm 2.4 \% \%^{a}$ & $-2.0 \pm 0.4^{a}$ & $-18.5 \pm 4.0^{a}$ & $23.0 \pm 4.1^{a}$ \\
\hline 904 & $-18.0 \pm 4.1 \%{ }^{a}$ & $-2.8 \pm 0.9^{a}$ & $-27.9 \pm 6.3^{a}$ & $35.0 \pm 6.0^{a}$ \\
\hline
\end{tabular}

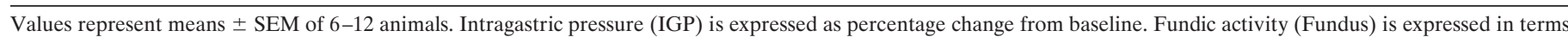

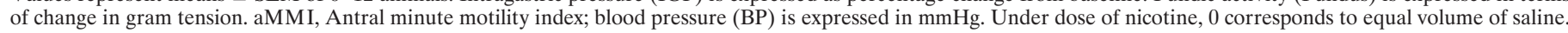
${ }^{a} p<0.05$ using ANOVA followed by Duncan's, as compared with saline controls.

(mmHg) was used. The mean blood pressure over a 3 min period was taken before drug microinjections or i.v. drug dosing. This value did not differ significantly from other 3 min values in the baseline. These baseline values were compared with the mean of the blood pressure trace $30 \mathrm{sec}$ after microinjections (which corresponded to the peak response, in this case a decrease in blood pressure) or after i.v. dosing (in this case an increase in blood pressure). Data appear as means (change in $\mathrm{mmHg}$ for blood pressure changes) \pm SEM.

For the calculations of the $\mathrm{ED}_{50}$ for agonist (nicotine and cytisine) dose-response curves, the Allfit program (DeLean et al., 1987) or sigmoidal dose-response (GraphPad, San Diego, CA) was used. In calculating the $\mathrm{ED}_{50}$ in the dose range tested in this study, the point that gave the maximal response was taken as the $\mathrm{ED}_{\max }$, and it extended to give the curve a definable plateau. This is a standard procedure when studying nicotinic receptors because a bell-shaped dose-response curve will eventually occur. Therefore, the top point of the curve is taken as the $\mathrm{ED}_{\text {max }}$, which does not always correspond to the highest dose tested, and is used as the plateau of the doseresponse curve. This is especially important because desensitization of nicotinic receptors has been shown to be dose dependent (Luetje and Patrick, 1991; Harvey and Luetje, 1996). Therefore, the maximal effect was used as the plateau to minimize the effect of desensitization. The effects of vehicle microinjection into the mNTS on intragastric and blood pressures were used as the zero point for the curves. Then, all mean responses elicited at the doses in between the $\mathrm{ED}_{\max }$ and the zero point were entered. These values were used to define an approximate $\mathrm{ED}_{50}$ for the doses tested in this study.

In establishing the dose-response curves for nicotine and cytisine, rats were usually given two doses of one of these agents. In some experiments, rats were microinjected with nicotine followed by the equivalent dose of cytisine. Fifteen minutes were allowed between all microinjections to obtain reproducible responses. It was common to obtain two sets of data points from each animal because drugs were given unilaterally. These data never differed from those in which only one set of data was obtained.

For studies using DHBE, the percentage of the response that was blocked was calculated by comparing the post-antagonist response to the pre-antagonist response. For the calculations of the $\mathrm{IC}_{50}$ for antagonists, the inhibition curves were constructed using different concentrations of the antagonist. For example, the effects of varying doses of DHBE (0.1-1000 pmol) to inhibit the decrease in IGP elicited from the mNTS with $10 \mathrm{pmol}$ of nicotine were included in the calculations and compared with the effect after microinjection of vehicle. These values were used to define an approximate $\mathrm{IC}_{50}$ for the doses of DHBE tested in this study. The $\mathrm{IC}_{50}$ value for DHBE was determined by nonlinear least-squares regression analyses (sigmoidal dose-response; GraphPad).

In all cases, statistical analysis was performed on both percentage change and raw data. Paired-samples $t$ test was performed when animals served as their own controls. Independent-sample $t$ test was performed on data from separate control and experimental groups. Comparisons among more than two means from different groups of rats were made by ANOVA followed by Duncan's multiple range test.
Differences were considered significant at $p<0.05$. All values are expressed as mean $\pm \mathrm{SEM}$.

\section{RESULTS}

\section{Effects of intravenously administered nicotine on gastric tone and motility and on arterial blood pressure}

Nicotine was administered intravenously over $\sim 30 \mathrm{sec}$ (see Materials and Methods) at doses of 56.5, 113, 226, 452, and 904 $\mathrm{nmol} / \mathrm{kg}$. The endpoints of gastric mechanical function measured were IGP, tonic contractions of the fundus, and phasic contractions of the antrum. Mean arterial blood pressure was also monitored. Data obtained are tabulated in Table 1. At the lowest dose studied, $56.5 \mathrm{nmol} / \mathrm{kg}$, nicotine produced a statistically significant

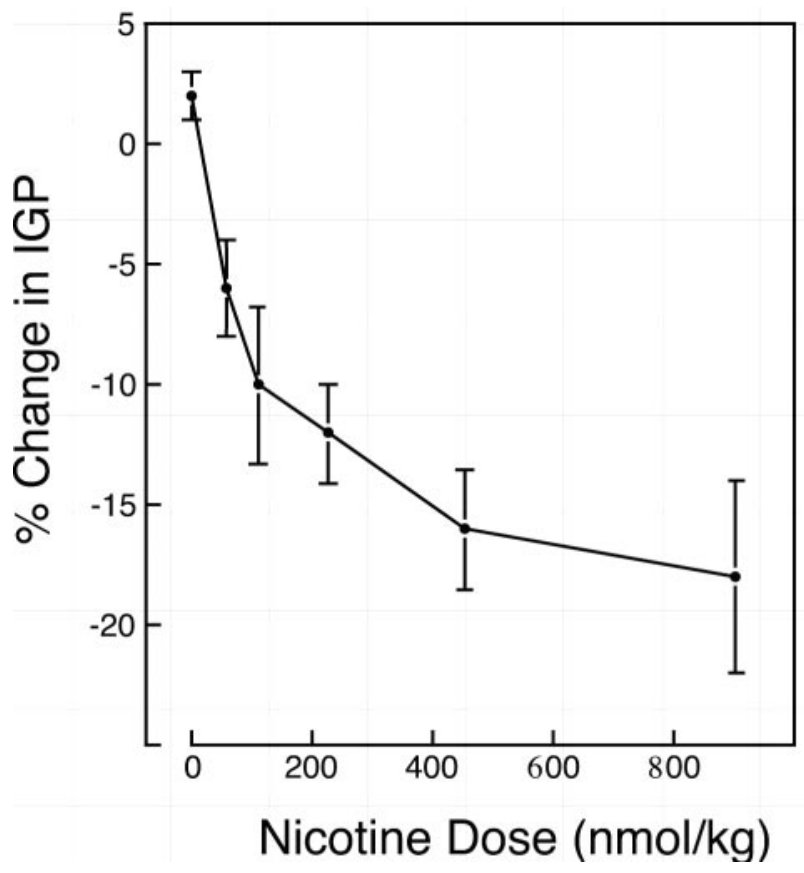

Figure 1. Dose-dependent decreases in intragastric pressure (IGP) produced by intravenously administered nicotine in the anesthetized rat. In each experiment, saline or nicotine given in doses of 56.5, 113, 226, 452, or $904 \mathrm{nmol} / \mathrm{kg}$ were administered. Animals that received saline (zero nicotine) were then given one of the doses of nicotine $30 \mathrm{~min}$ later. Animals never received a second dose of nicotine. Each data point corresponds to the mean \pm SEM of the responses of $6-12$ animals. 


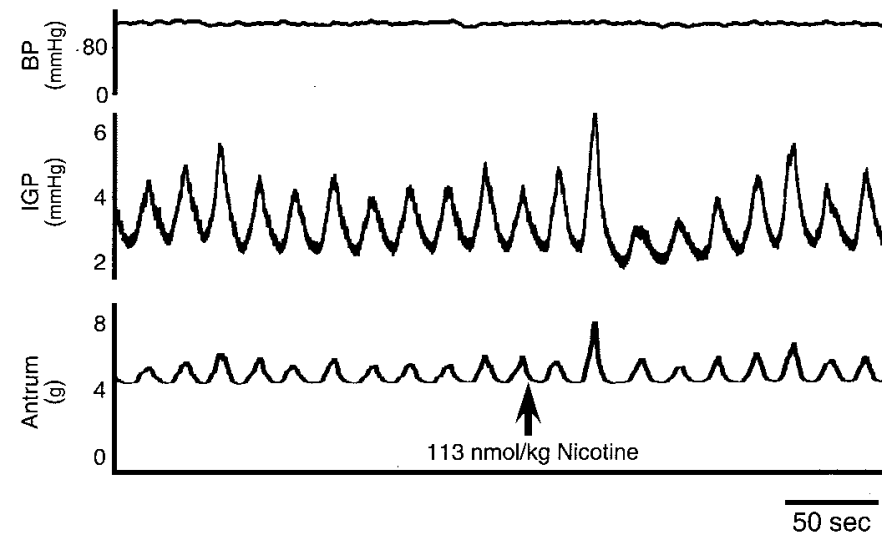

Figure 2. Tracings showing the effects of intravenously administered nicotine $(113 \mathrm{nmol} / \mathrm{kg})$ on blood pressure $(B P)$, intragastric pressure $(I G P)$, and antral motility (Antrum). The scales for the acquisition records of BP, IGP, and antrum have been adjusted to reflect their activity. Note: the transient increase in phasic pressure before its decrease is caused by normal variability and therefore independent of nicotine administration.

decrease in IGP, but no statistically significant changes were observed on the other indices of gastric mechanical and cardiovascular function that were measured. With doses of 113 and 226 $\mathrm{nmol} / \mathrm{kg}$, in addition to producing dose-related decreases in IGP (Fig. 1), nicotine also produced dose-related decreases in tonic contractions of the fundus (Table 1). As with the lowest dose of nicotine tested, there were no statistically significant changes in the phasic contractions of the antrum or mean arterial blood pressure. In contrast, at the highest two doses tested, 452 and 904 $\mathrm{nmol} / \mathrm{kg}$, nicotine evoked statistically significant changes in all four indices of gastric mechanical and cardiovascular functions measured: decreases in IGP, tonic contractions of the antrum and fundus, and increases in blood pressure were all observed (Table 1). Dose-related effects of nicotine on IGP are displayed in Figure 1 , and representative experiments indicating the time course of effects with both a low dose $(113 \mathrm{nmol} / \mathrm{kg})$ and a "high" dose of nicotine (452 nmol/kg) appear as Figures 2 and 3, respectively.

To determine whether responses obtained with representative low and high intravenously administered doses of nicotine could be reproduced in the same animal, a second administration of one of these doses was made 20-30 min after the first dose was given. The data are tabulated in Table 2 and indicate that IGP and

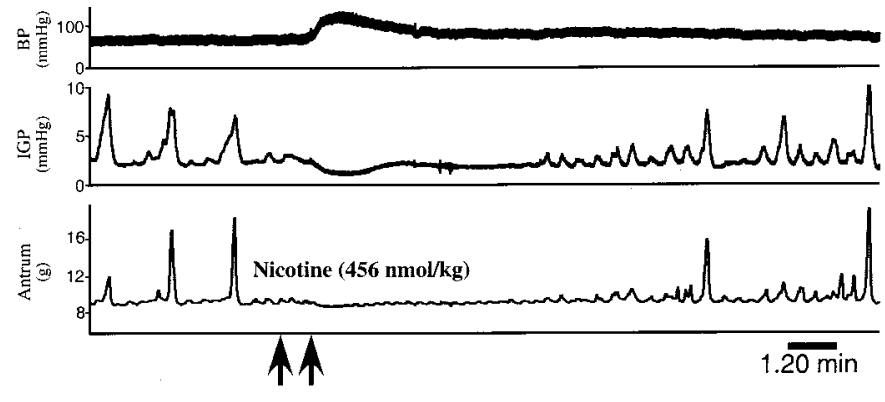

Figure 3. Tracings showing the effects of intravenously administered nicotine $(452 \mathrm{nmol} / \mathrm{kg})$ on blood pressure $(B P)$, intragastric pressure $(I G P)$, and antral motility (Antrum). Double arrows indicate start and stop of nicotine infusion. Note: the scales for the acquisition records of BP, IGP, and antrum have been adjusted to reflect their activity.

fundus responses evoked by the $113 \mathrm{nmol} / \mathrm{kg}$ dose of nicotine were not repeatable; responses of IGP and fundus were only approximately one-third of the values obtained after the first administration of nicotine. However, this was not the case with the $452 \mathrm{nmol} / \mathrm{kg}$ dose of nicotine in which responses evoked on IGP, fundus, antrum, and mean arterial blood pressure were all reproduced by the second administration of nicotine 20-30 min after the first $452 \mathrm{nmol} / \mathrm{kg}$ dose had been given (Table 2).

Next, effects of bilateral cervical vagotomy were studied on i.v. nicotine-induced responses. We could not use each animal as its own control; that is, we could not get a control response with nicotine and repeat the same nicotine dose after vagotomy because of the lack of repeatability of a second dose of i.v. nicotine administered 20-30 min after the initial dose of nicotine (Table 2). Hence, the first dose of i.v. nicotine was tested after cervical vagotomy, and only IGP and fundus effects were evaluated. The rationale for examining only IGP and fundus effects was that i.v. doses of 113 and $226 \mathrm{nmol} / \mathrm{kg}$ affected only these two indices of gastric mechanical function and had no effect on the antrum or on the mean arterial blood pressure (Table 1). Nicotine administered as a first dose of 113 and $226 \mathrm{nmol} / \mathrm{kg}$ in these vagotomized animals had relatively little effect on IGP and tonic activity of the fundus. This was especially true of the effects of the 113 and 226 $\mathrm{nmol} / \mathrm{kg}$ doses on IGP and the $226 \mathrm{nmol} / \mathrm{kg}$ dose on the tonic contractions of the fundus. With the $452 \mathrm{nmol} / \mathrm{kg}$ i.v. dose of nicotine, the effects on IGP, and fundus were not altered by vagotomy (Table 3 ).

\begin{tabular}{|c|c|c|c|c|}
\hline \multirow{2}{*}{$\begin{array}{l}\text { Dose of nicotine } \\
(\mathrm{nmol} / \mathrm{kg})\end{array}$} & \multicolumn{4}{|c|}{ Effects of nicotine on } \\
\hline & IGP & Fundus & aMMI & $\mathrm{BP}$ \\
\hline \multicolumn{5}{|l|}{113} \\
\hline First dose & $-9.0 \pm 1.1 \%$ & $-1.1 \pm 0.3$ & $6.7 \pm 3.2$ & $6.0 \pm 2.5$ \\
\hline Second dose & $-3.0 \pm 0.7 \%^{a}$ & $-0.3 \pm 0.1^{a}$ & $4.9 \pm 5.2$ & $8.0 \pm 2.2$ \\
\hline \multicolumn{5}{|l|}{452} \\
\hline First dose & $-18.2 \pm 2.7 \%$ & $-1.9 \pm 0.4$ & $-16.6 \pm 3.3$ & $26.4 \pm 7.2$ \\
\hline Second dose & $-17.1 \pm 2.4 \%$ & $-2.1 \pm 0.7$ & $-19.5 \pm 4.1$ & $31.4 \pm 6.5$ \\
\hline
\end{tabular}

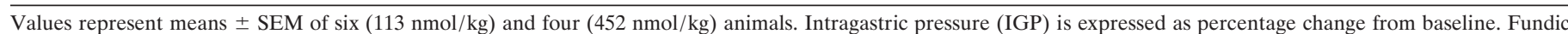

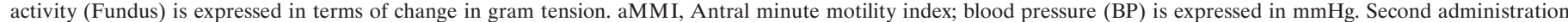
of nicotine was given 20-30 min later.

${ }^{a} p<0.05$ using paired Student's $t$ test, compared with first dose of nicotine. 
Table 3. Effects of bilateral cervical vagotomy on i.v. nicotine-induced changes in intragastric pressure and tonic contraction of the fundus

\begin{tabular}{lcr}
$\begin{array}{l}\text { Dose of nicotine } \\
(\mathrm{nmol} / \mathrm{kg})\end{array}$ & \multicolumn{2}{l}{ Effects of nicotine on } \\
\cline { 2 - 3 } & IGP & \multicolumn{1}{l}{ Fundus } \\
\hline 113 & $2.1 \pm 1.8 \%^{a}$ & $1.2 \pm 0.5^{a}$ \\
226 & $-3.6 \pm 1.0 \%^{a}$ & $-0.3 \pm 0.9^{a}$ \\
452 & $-11.4 \pm 3.2 \%$ & $-2.3 \pm 0.2$
\end{tabular}

Values represent means \pm SEM of three to five animals. Intragastric pressure (IGP) is expressed as percentage change from baseline. Fundic activity (Fundus) is expressed in terms of change in gram tension.

${ }^{a} p<0.05$ using ANOVA followed by Duncan's, as compared with data tabulated in Tables 1 and 2 obtained with first dose of nicotine in vagus nerve intact animals.

\section{Effects of hexamethonium or vehicle administered into either the mNTS or the DMV on intravenous nicotine- induced effects on gastric tone and motility and on arterial blood pressure}

In an earlier published study we reported that nicotine microinjected into the mNTS of anesthetized rats could produce doserelated decreases in IGP (Ferreira et al., 2000), similar to those obtained in the present study by intravenously administered nicotine. We also reported that the nAChR antagonist, hexamethonium $(1 \mathrm{nmol} / 60 \mathrm{nl})$, microinjected into the mNTS could prevent nicotine microinjected into the mNTS from decreasing IGP (Ferreira et al., 2000). To determine whether nicotine administered intravenously exerts its effect on IGP and tonic contractions of the fundus by an action in the brain, we performed a series of experiments wherein $1 \mathrm{nmol}$ of hexamethonium was first microinjected into the mNTS bilaterally, and then i.v. doses of 113, 226, and $452 \mathrm{nmol} / \mathrm{kg}$ nicotine were evaluated with regard to their effects on IGP, tonic contractions of the fundus, phasic contractions of the antrum, and mean arterial blood pressure. Data are tabulated in Table 4 and indicate that hexamethonium microinjected into the mNTS counteracted i.v. doses of 113 and 226 $\mathrm{nmol} / \mathrm{kg}$ nicotine on IGP and tonic contractions of the fundus. As a control experiment, bilateral microinjections of $1 \mathrm{nmol} / 60 \mathrm{nl}$ of hexamethonium were also made into the DMV. Hexamethonium microinjected into this brainstem site had no significant effect on IGP and tonic fundus contractions produced by i.v. doses of 113 and $226 \mathrm{nmol} / \mathrm{kg}$ nicotine (Table 4). Finally, hexamethonium microinjected $(1 \mathrm{nmol} / 60 \mathrm{nl})$ bilaterally into either the mNTS or the DMV had no significant effects on the i.v. doses of 452 $\mathrm{nmol} / \mathrm{kg}$ nicotine on IGP, fundus, antrum, and mean arterial blood pressure (Table 4). Finally, hexamethonium, per se, microinjected into either the mNTS or the DMV (unilateral or bilateral), had no significant effect on IGP, fundus, or antrum (data not shown). The microinjection sites for hexamethonium into the mNTS and DMV are depicted in Figure 4.

\section{Effects of intravenous doses of nicotine on c-Fos expression in brainstem nuclei}

For c-Fos studies to be optimal, experiments need to be performed in conscious animals. Hence, in our studies we used the same five doses of intravenous nicotine that we used in anesthetized animals (Table 1) and administered each of these doses intravenously to conscious rats. A control group that received an equal volume of i.v. saline was also studied. Experiments were terminated $1 \mathrm{hr}$ after injection of nicotine (or saline), and brains were harvested and examined for the presence of c-Fos (mNTS) and/or c-Fos plus Fluorogold (DMV). Data are summarized and presented in Table 5 and indicate the following. (1) Nicotine doses of $56.5,113$, and $226 \mathrm{nmol} / \mathrm{kg}$ produced significant increases in c-Fos in the mNTS relative to the effect of saline vehicle. The increases in c-Fos expression that occurred were similar for all three doses of nicotine. (2) With the two highest doses of nicotine, namely, 452 and $904 \mathrm{nmol} / \mathrm{kg}$, c-Fos expression in the mNTS exhibited an additional increase that appeared greater than that noted with the lower three doses; and (3) no dose of nicotine used here had a significant effect on c-Fos expression in DMV neurons that project to the stomach (Table 5). In other words, counts for c-Fos in retrogradely labeled (Fluorogold positive) DMV neurons of rats exposed to nicotine and to saline vehicle were not significantly different from each other. A visual comparison of c-Fos label in mNTS neurons and in double-labeled DMV neurons after saline, i.v. nicotine 56.5 $\mathrm{nmol} / \mathrm{kg}$, and i.v. nicotine $904 \mathrm{nmol} / \mathrm{kg}$ appears in Figure 5. Note the lack of c-Fos labeling after saline vehicle. Also, note the dose-related increase in c-Fos label between 56.5 and 904 $\mathrm{nmol} / \mathrm{kg}$ i.v. nicotine. Labeled cells appear primarily in the mNTS. Finally, note the lack of c-Fos labeling of DMV neurons projecting to the stomach after both doses of nicotine.

\section{Studies to determine the nAChR subtype at the mNTS responsible for nicotine-induced changes in gastric mechanical and cardiovascular functions}

The mNTS hexamethonium microinjection experiments and the c-Fos expression experiments both suggested that the mNTS was a likely site of action of i.v. nicotine-induced changes in IGP and fundus tonic contractions. The goal of studies in this section was to determine the subtype of $\mathrm{nAChR}$ responsible for these nicotine-evoked responses. Two pharmacological approaches were used: namely, mNTS microinjection of cytisine, an agent that stimulates $\mathrm{nAChRs}$ that contain a $\beta 4$ subunit but is relatively inactive at $\mathrm{nAChRs}$ that contain a $\beta 2$ subunit (Luetje and Patrick, 1991); and mNTS microinjection of DHBE, a potent antagonist of nAChRs that contain a $\beta 2$ subunit but is much less potent at $\mathrm{nAChRs}$ that contain a $\beta 4$ and or $\alpha 7$ subunit (Harvey and Luetje, 1996).

Data obtained with cytisine microinjected into the mNTS on IGP, tonic contractions of the fundus, phasic contractions of the antrum, and mean arterial blood pressure are summarized in Figure 6. Comparative data are also presented for nicotine. As can be noted, cytisine microinjected into the mNTS in doses ranging from 1 to $1000 \mathrm{pmol} / 60 \mathrm{nl}$ had no significant effect on either IGP or tonic contractions of the fundus (Fig. 6 $A, B$ ). These data contrast with data obtained with microinjected nicotine in which a dose range of 0.1 to $1000 \mathrm{pmol} / 60 \mathrm{nl}$ evoked dose-related decreases in IGP and tonic contractions of the fundus. Cytisine, however, was as effective as nicotine in producing decreases in phasic contraction of the antrum (Fig. 6C). In terms of mean arterial blood pressure effects, as reported previously by our group (Ferreira et al., 2000), nicotine microinjected into the $\mathrm{mNTS}$ results in a decrease in mean arterial blood pressure (Fig. $6 D$ ), and this effect is also noted with microinjections of cytisine into the mNTS (Fig. 6D). The $\mathrm{ED}_{50}$ values for nicotine-induced decreases in IGP, fundus tone, antral motility, and mean arterial blood pressure were $0.75,4.0,13.5$, and 6.3 pmol, respectively. Comparative $\mathrm{ED}_{50}$ values for cytisine-induced decreases in antral motility and mean arterial blood pressure were 8.5 and 5.0 pmol, respectively.

The second pharmacological approach used to identify the 
Table 4. Effects of hexamethonium or vehicle microinjected bilaterally into either the mNTS or the DMV on i.v. nicotine-induced changes in intragastric pressure, tonic contraction of the fundus, motility of the antrum, and mean arterial blood pressure

\begin{tabular}{|c|c|c|c|c|c|}
\hline \multirow{2}{*}{$\begin{array}{l}\text { Dose of nicotine } \\
(\mathrm{nmol} / \mathrm{kg})\end{array}$} & \multirow[b]{2}{*}{ Pretreatment } & \multicolumn{4}{|c|}{ Effects of nicotine on } \\
\hline & & IGP & Fundus & aMMI & $\mathrm{BP}$ \\
\hline \multirow[t]{3}{*}{113} & Saline (mNTS) & $-11.6 \pm 2.3 \%$ & $-1.2 \pm 0.2$ & $-3.8 \pm 2.1$ & $2.0 \pm 4.2$ \\
\hline & HEX (mNTS) & $-1.5 \pm 3.3 \%{ }^{a}$ & $0.3 \pm 0.4^{a}$ & $2.5 \pm 3.1$ & $-3.7 \pm 5.0$ \\
\hline & HEX (DMV) & $-10.1 \pm 1.8 \%$ & $-1.5 \pm 0.6$ & $3.9 \pm 5.6$ & $-5.5 \pm 2.4$ \\
\hline \multirow[t]{3}{*}{226} & Saline (mNTS) & $-13.6 \pm 3.8 \%$ & $-1.6 \pm 0.3$ & $-6.9 \pm 7.1$ & $6.3 \pm 2.5$ \\
\hline & HEX (mNTS) & $-4.5 \pm 1.4 \%^{a}$ & $-0.5 \pm 0.4^{a}$ & $3.5 \pm 1.4$ & $3.9 \pm 4.6$ \\
\hline & HEX (DMV) & $-12.6 \pm 2.9 \%$ & $-1.2 \pm 0.6$ & $-4.3 \pm 1.4$ & $2.9 \pm 5.1$ \\
\hline \multirow[t]{3}{*}{452} & Saline (mNTS) & $-19.3 \pm 4.2 \%$ & $-2.1 \pm 0.6$ & $-20.3 \pm 4.2$ & $23.7 \pm 3.5$ \\
\hline & HEX (mNTS) & $-18.6 \pm 3.2 \%$ & $-2.4 \pm 0.4$ & $-22.5 \pm 3.9$ & $19.9 \pm 3.0$ \\
\hline & HEX (DMV) & $-19.8 \pm 2.9 \%$ & $-2.5 \pm 0.8$ & $-19.8 \pm 1.4$ & $24.1 \pm 2.4$ \\
\hline
\end{tabular}

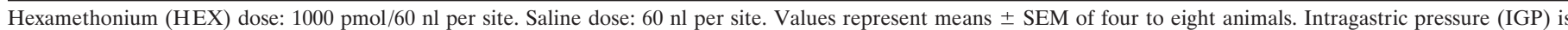

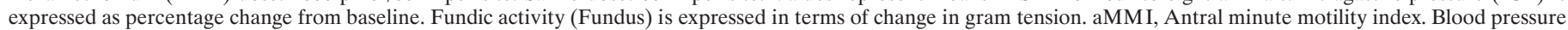
(BP) is expressed in mmHg.

${ }^{a} p<0.05$ using ANOVA followed by Duncan's, compared with saline-treated group.

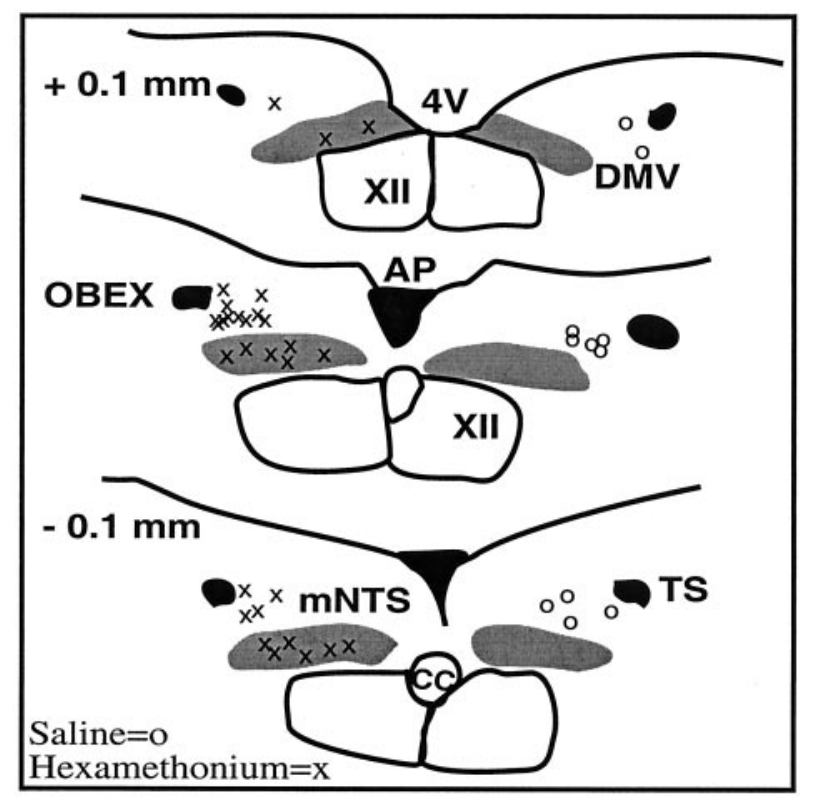

Figure 4. Camera lucida drawings showing microinjection sites of hexamethonium or saline into the dorsal medulla. Hexamethonium $(1000$ $\mathrm{pmol} / 60 \mathrm{nl}$ per injection) was microinjected bilaterally into either the mNTS or the DMV to test the ability of this agent to block i.v. nicotine $(113 \mathrm{nmol} / \mathrm{kg})$ effects on gastric mechanical endpoints. All hexamethonium microinjections into the mNTS or the DMV are shown on the left, whereas the saline microinjections into the mNTS are shown on the right. Injections were usually found to be $0.1 \mathrm{~mm}$ caudal $(-0.1 \mathrm{~mm})$ to $0.1 \mathrm{~mm}$ rostral $(+0.1 \mathrm{~mm})$ to obex. $4 V$, Fourth ventricle; $D M V$, dorsal motor nucleus of the vagus nerve; $X I I$, hypoglossal nucleus; $A P$, area postrema; $T S$, tractus solitarius; $m N T S$, medial subnucleus of the tractus solitarius; $c c$, central canal.

nAChR subtype in the mNTS involved the use of a highly potent antagonist of the $\beta 2$-containing $\mathrm{nAChR}$, DHBE. In our studies with DHBE, we characterized the full inhibition curve on nicotine-induced decreases in IGP, tonic contractions of the fundus, phasic contractions of the antrum, and mean arterial blood pressure. DHBE was studied using doses of $0.1-1000$ pmol in 60 $\mathrm{nl}$, and nicotine was studied using a dose of $10 \mathrm{pmol} / 60 \mathrm{nl}$. Data obtained are summarized in Figure 7, and as can be noted, DHBE
Table 5. Effects of nicotine administration to conscious rats on c-Fos levels in the mNTS and in DMV neurons projecting to the stomach

\begin{tabular}{|c|c|c|c|}
\hline \multirow{2}{*}{$\begin{array}{l}\text { Dose of nicotine } \\
(\mathrm{nmol} / \mathrm{kg})\end{array}$} & \multirow{2}{*}{$\begin{array}{l}\text { Number of } \\
\text { animals }\end{array}$} & \multicolumn{2}{|c|}{ c-Fos + cells in the } \\
\hline & & mNTS & DMV \\
\hline \multirow[t]{2}{*}{0} & 4 (mNTS) & $5.9 \pm 0.7$ & 0.0 \\
\hline & 3 (DMV) & & \\
\hline \multirow[t]{2}{*}{56.5} & $4(\mathrm{mNTS})$ & $49.3 \pm 8.9^{a}$ & 0.3 \\
\hline & $1(\mathrm{DMV})$ & & \\
\hline \multirow[t]{2}{*}{113} & $3(\mathrm{mNTS})$ & $42.4 \pm 8.7^{a}$ & 0.0 \\
\hline & 2 (DMV) & & \\
\hline \multirow[t]{2}{*}{226} & $3(\mathrm{mNTS})$ & $52.2 \pm 2.2^{a}$ & 0.1 \\
\hline & 1 (DMV) & & \\
\hline \multirow[t]{2}{*}{452} & $3(\mathrm{mNTS})$ & $78.3 \pm 7.1^{a}$ & 0.2 \\
\hline & $2(\mathrm{DMV})$ & & \\
\hline \multirow[t]{2}{*}{904} & $6(\mathrm{mNTS})$ & $129.4 \pm 11.5^{a}$ & 1.0 \\
\hline & $2(\mathrm{DMV})$ & & \\
\hline
\end{tabular}

mNTS numbers are the average number of neurons exhibiting c-Fos per transverse section. DMV numbers are the average number of double-labeled neurons (i.e., c-Fos + and Fluorogold + ) exhibiting c-Fos per transverse section.

${ }^{a} p<0.05$ using ANOVA followed by Student's-Newman-Keuls, as compared with the zero (saline) dose animals.

had a more potent blocking effect on nicotine-induced decreases in IGP and tonic contractions of the fundus than on nicotineinduced decreases in phasic contractions of the antrum and mean arterial blood pressure. DHBE blocked $\sim 80$ and $60 \%$ of nicotineinduced decreases in IGP and fundus tonic contractions at a dose of 0.1 pmol, respectively. At $10 \mathrm{pmol}$ of DHBE, we observed a significant blockade of the responses of nicotine on the antrum and on mean arterial blood pressure. Analysis of data obtained with all five doses of $\mathrm{DHBE}$ indicated $\mathrm{IC}_{50}$ values for antagonizing nicotine-induced responses on IGP, fundus tonic contractions, antrum phasic contractions, and mean arterial blood pressure of $0.3,0.7,15.2$, and 290 pmol, respectively.

On the basis of our findings that DHBE microinjected into the mNTS could selectively block nicotine microinjected into the mNTS on IGP and fundus tonic contractions, we next tested whether bilateral microinjection of DHBE, 1 pmol, into the mNTS could counteract the IGP and fundus effects of i.v. nicotine. Data obtained are summarized in the histograms shown in 

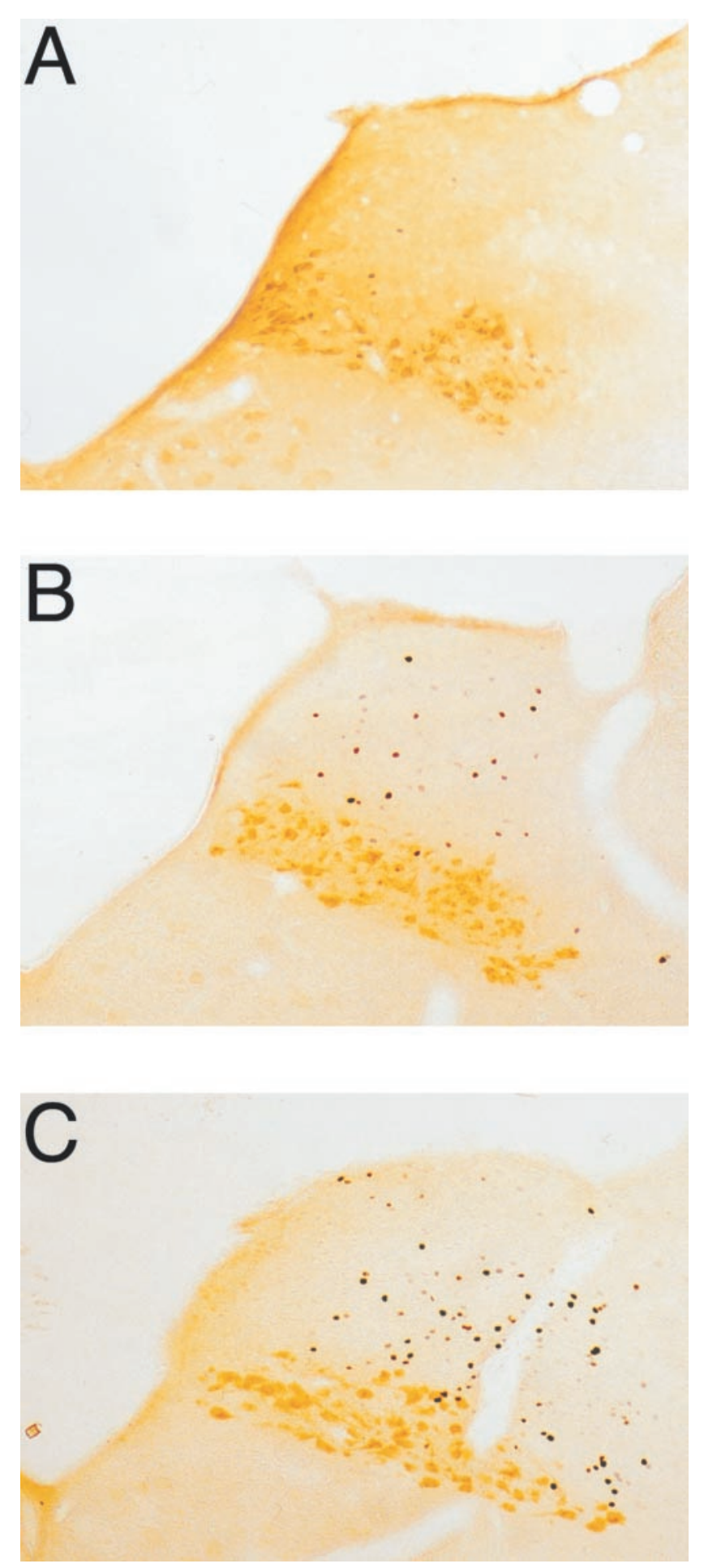

Figure 5. Photomicrographs of tissue sections through the rostral dorsomedial medulla double labeled for c-Fos and Fluorogold after intravenous administration of different doses of nicotine. $A$, Isotonic saline; $B$, nicotine, $56.5 \mathrm{nmol} / \mathrm{kg}$; $C$, nicotine, $904 \mathrm{nmol} / \mathrm{kg}$. Cells activated to express c-Fos (black nuclear stain) were found predominantly in the medial NTS, and the number of c-Fos-positive cells increased in relation to the dose of nicotine administered. Cells of the dorsal motor nucleus of the vagus $(D M V)$ were identified by the presence of Fluorogold (golden-brown cytoplasmic stain), which was transported retrogradely after systemic injections $5 \mathrm{~d}$ before perfusion. Although an occasional c-Fos-positive nucleus can be seen within the anatomical confines of the DMV, inspection under higher power showed that very few cells actually were doublelabeled cells with both c-Fos and Fluorogold.
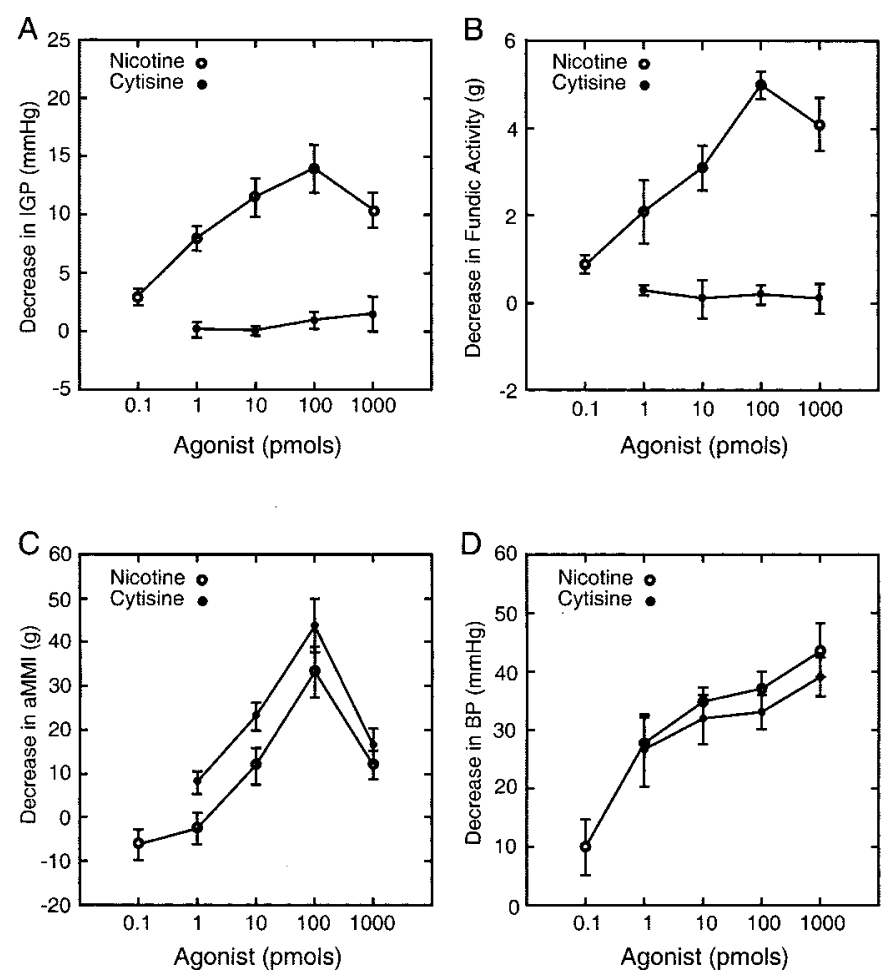

Figure 6. Dose-response curves of nicotine and cytisine microinjected into the mNTS on intragastric pressure $(I G P)(A)$, fundic activity $(B)$, antral motility $(a M M I)(C)$, and blood pressure $(B P)(D)$. In each experiment, nicotine was first microinjected followed by cytisine (in the same dose as nicotine) or nicotine again. The interval between the first dose of nicotine and the later dose of either cytisine or nicotine was $15 \mathrm{~min}$. Intragastric pressure responses are expressed as percentage changes from baseline. Fundic activity responses are indicated by decreases in tonic gastric contraction from baseline expressed in grams $(g)$. Antral MMI responses are expressed as changes in aMMI. Decreases in BP are expressed in $\mathrm{mmHg}$. Each point corresponds to the mean \pm SEM of the responses of 6-10 microinjections for cytisine and 12-20 microinjections for nicotine.

Figure 8. As can be noted, DHBE pretreatment into the mNTS counteracted the effects of i.v. nicotine, $113 \mathrm{nmol} / \mathrm{kg}$, to decrease IGP and tonic contractions of the fundus. Microinjection of DHBE unilaterally or bilaterally did not have effects, per se, on any endpoints monitored.

\section{Vagal contribution to nicotine-induced effects from the mNTS}

In performing studies of nicotine microinjected into the mNTS, the question arose as to whether the gastric mechanical effects of this agent were mediated through activation of the vagus nerves (as in the case of intravenously administered nicotine tabulated in Table 3). These studies could be performed using repeat microinjections of nicotine into the mNTS, because no diminution of responses occur when the interval between microinjections is 15 min (Ferreira et al., 2000). Mediation of responses by the vagus nerves was assessed by performing ipsilateral and bilateral cervical vagotomy before and after evoking responses with 10 pmol nicotine microinjected unilaterally into the mNTS, and the data obtained are tabulated in Table 6. As can be noted, bilateral (but not unilateral) vagotomy counteracted nicotine-induced decreases in IGP, fundus tonic contractions, and antrum phasic contractions. 


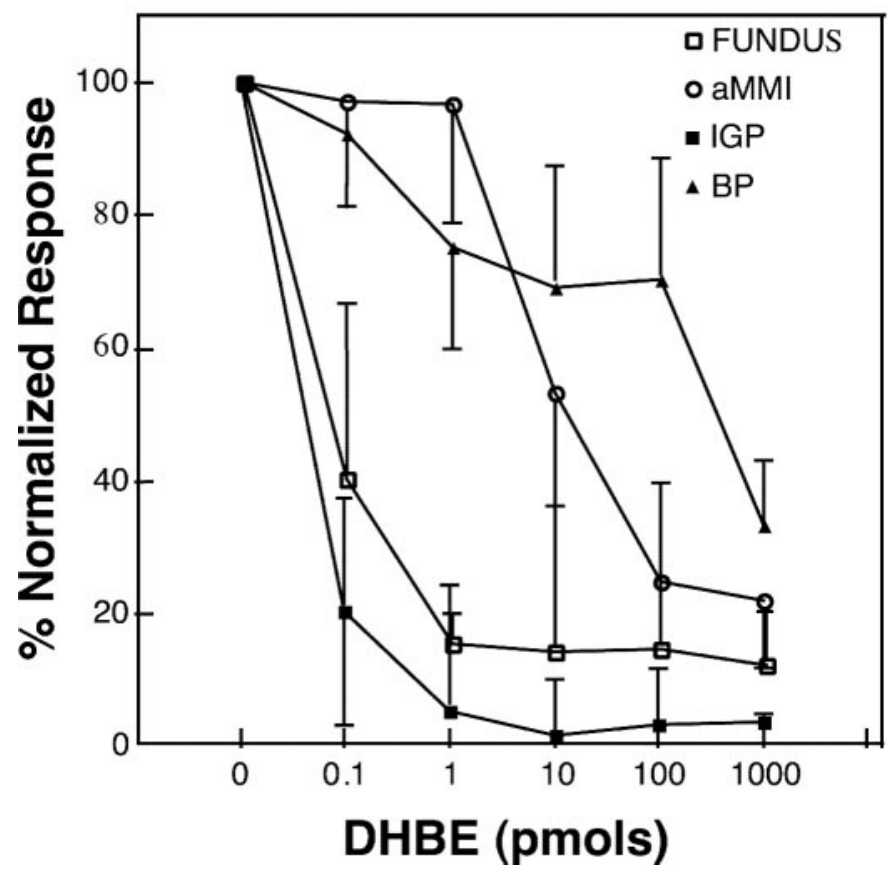

Figure 7. Dose-dependent inhibition of nicotine-induced (10 pmol/60 nl) decreases in IGP, fundus activity, antral activity, and BP by DHBE. Nicotine-induced decreases in IGP, fundus activity, antral activity, and BP were inhibited by increasing doses of DHBE $(0.1-1000 \mathrm{pmol} / 60 \mathrm{nl})$. Experiments were conducted by first microinjecting nicotine; then DHBE was microinjected $15 \mathrm{~min}$ later, followed by nicotine again 5 min after DHBE. The data point coinciding with 0 on the log scale represents data obtained with zero antagonist (before DHBE is microinjected). Data are normalized to values obtained in the same animals with microinjection of nicotine alone. The number of microinjection sequences tested with each dose of DHBE was 6-10 microinjections (4-8 animals). Data are expressed as percentage of initial response to nicotine \pm SEM.

Bilateral cervical vagotomy had no effect on nicotine-induced decreases in mean arterial blood pressure (Table 6).

It should be noted that it is not possible to conclude that a drug microinjected into a CNS site evokes peripheral responses mediated by the vagus nerves based on just performing bilateral cervical vagotomy [although we have erroneously drawn such a conclusion in the past (Ferreira et al., 2000)]. That is, it is possible that the central action of a drug on the stomach can occur through a non-vagal pathway that nonetheless requires vagal tone for its actions (see Materials and Methods) (Humphreys et al., 1992). To evaluate this possibility, three experiments were performed wherein the distal cut portions of cervical vagal nerves were stimulated electrically, and nicotine was microinjected into the mNTS to determine whether it would still reduce IGP in these bilaterally vagotomized animals. In each case $(n=3)$, nicotine, 10 pmol, exerted no effect on IGP. A representative experiment appears as Figure 9.

\section{Studies to determine the location of the $\mathrm{AAChR}$ in the mNTS}

Neuronal nicotinic acetylcholine receptors in the CNS are known to be located at both presynaptic and postsynaptic sites, although the best evidence is for affecting a presynaptic function involving the release of a number of neurotransmitters (Colquhoun and Patrick, 1997), including glutamate (McGehee and Role, 1995). Because glutamate is considered to be the neurotransmitter of

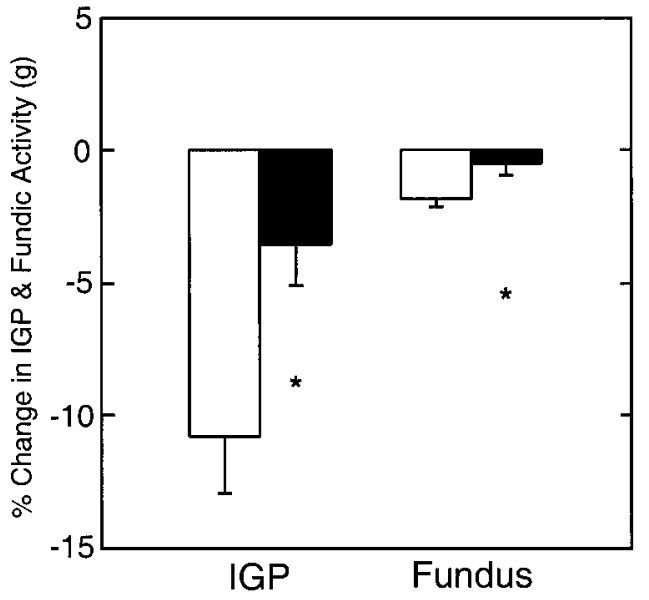

Figure 8. Effect of DHBE or vehicle microinjections into the mNTS bilaterally on i.v. nicotine-induced changes in intragastric pressure $(I G P)$ and tonic contraction of the fundus. Saline $(60 \mathrm{nl})$ or DHBE (1 $\mathrm{pmol} / 60 \mathrm{nl}$ ) was microinjected into the $\mathrm{mNTS}$, and 5 min later, 113 $\mathrm{nmol} / \mathrm{kg}$ of i.v. nicotine was administered. White histograms show the changes in IGP and the fundus elicited by i.v. nicotine after saline was microinjected into the mNTS. Black histograms show changes elicited by i.v. nicotine after DHBE was microinjected into the mNTS. The saline (5 animals) and DHBE (8 animals) data are presented as the mean $\pm \mathrm{SEM} ; * p<0.05$ as compared with saline-treated groups of rats, using unpaired $t$ test.

vagal afferent nerve terminals in the mNTS (Talman et al., 1980), we hypothesized that nicotine might act at these presynaptic vagal terminals to release glutamate onto mNTS neurons. Another rationale for our hypothesis was that microinjection of nicotine into the mNTS mimicked the effect of microinjection of glutamate into the mNTS on IGP (Ferreira et al., 2000). To test our hypothesis, we determined whether a drug that blocks L-glutamate at ionotropic glutamate receptors, namely, kynurenic acid, would alter the effect of nicotine microinjected into the mNTS on IGP. Studies were conducted wherein kynurenic acid (100 pmol) was microinjected unilaterally into the mNTS after an initial microinjection of nicotine ( $10 \mathrm{pmol}$ into the same site). The nicotine-induced decrease in IGP was inhibited, whereas the decrease in mean blood pressure evoked by nicotine was unaffected (Fig. 10). The blockade by kynurenic acid was caused by blockade of glutamate receptors, because microinjection of saline

Table 6. Effects of vagotomy on unilateral microinjected nicotineinduced changes in intragastric pressure, tonic contractions of the fundus, phasic contractions of the antrum, and mean arterial blood pressure elicited from the mNTS

\begin{tabular}{lccr} 
mNTS & Pre-Vx & Post-ipsilateral Vx & Bilateral Vx \\
\hline IGP & $-10.4 \pm 1.8 \%$ & $-11.8 \pm 1.3 \%$ & $2.0 \pm 1.6^{a}$ \\
Fundus & $-2.6 \pm 0.6$ & $-2.8 \pm 0.4$ & $0.2 \pm 0.4^{a}$ \\
aMMI & $-14 \pm 2.8$ & $-15.3 \pm 4.4$ & $2.9 \pm 3.5^{a}$ \\
BP & $-29.7 \pm 3.4$ & $-37 \pm 4.8$ & $-31.3 \pm 7.4$
\end{tabular}

Nicotine microinjections were $10 \mathrm{pmol} / 60 \mathrm{nl}$. Values represent means \pm SEM of six animals. Intragastric pressure (IGP) is expressed as percentage change from baseline. Fundic activity (Fundus) is expressed in terms of change in gram tension. aMMI, Antral minute motility index. Blood pressure (BP) is expressed in $\mathrm{mmHg}$. Vx, Vagotomy.

${ }^{a} p<0.05$ compared with pre-Vx and post-ipsilateral Vx by using ANOVA followed by Duncan's. 

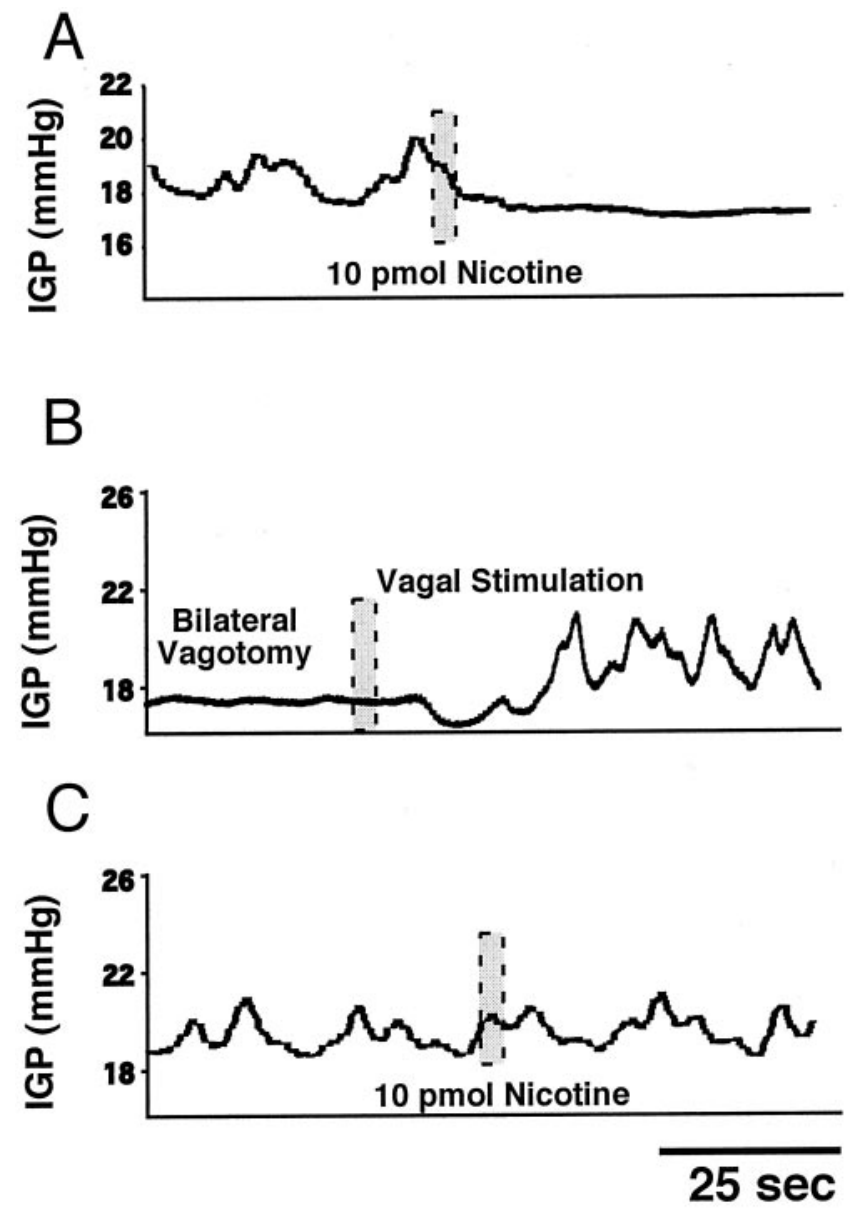

Figure 9. Unilateral microinjection of nicotine $(10 \mathrm{pmol} / 60 \mathrm{nl})$ into the mNTS caused a decrease in intragastric pressure $(I G P)$ in a vagally intact rat $(A)$ but not when the rat was bilaterally vagotomized during vagal nerve stimulation $(C)$. Note: the right vagus nerve was electrically stimulated throughout the traces shown in $C$. $B$ shows the IGP trace after bilateral vagotomy and after the start of vagal stimulation.

(vehicle) into the mNTS did not affect the nicotine-induced decrease in IGP (Fig. 10).

Effects of microinjection of either kynurenic acid or vehicle bilaterally into the mNTS were also assessed on gastric mechanical responses evoked by i.v. nicotine, $113 \mathrm{nmol} / \mathrm{kg}$. Kynurenic acid, $100 \mathrm{pmol} / 60 \mathrm{nl}$, or saline $(60 \mathrm{nl})$ was microinjected into the mNTS before testing i.v. nicotine, and the data are summarized in Figure 10. As can be seen, kynurenic acid but not vehicle prevented i.v. nicotine from decreasing both IGP and tonic contractions of the fundus. Kynurenic acid had no significant effects per se on either gastric endpoints or mean arterial blood pressure after microinjections unilaterally or bilaterally into the mNTS.

\section{Studies to determine the neurotransmitters in the central portion of the vago-vagal reflex that are responsible for mediating the effects of nicotine}

The finding of NADPH staining [which is a marker for neuronal nitric oxide synthetase (NOS)-diaphorase activity] in a cell cluster within the mNTS (Ruggiero et al., 1996) focused our attention on the possibility that NO might be involved in nicotine-induced effects at the mNTS. To test for involvement of NO in mediating
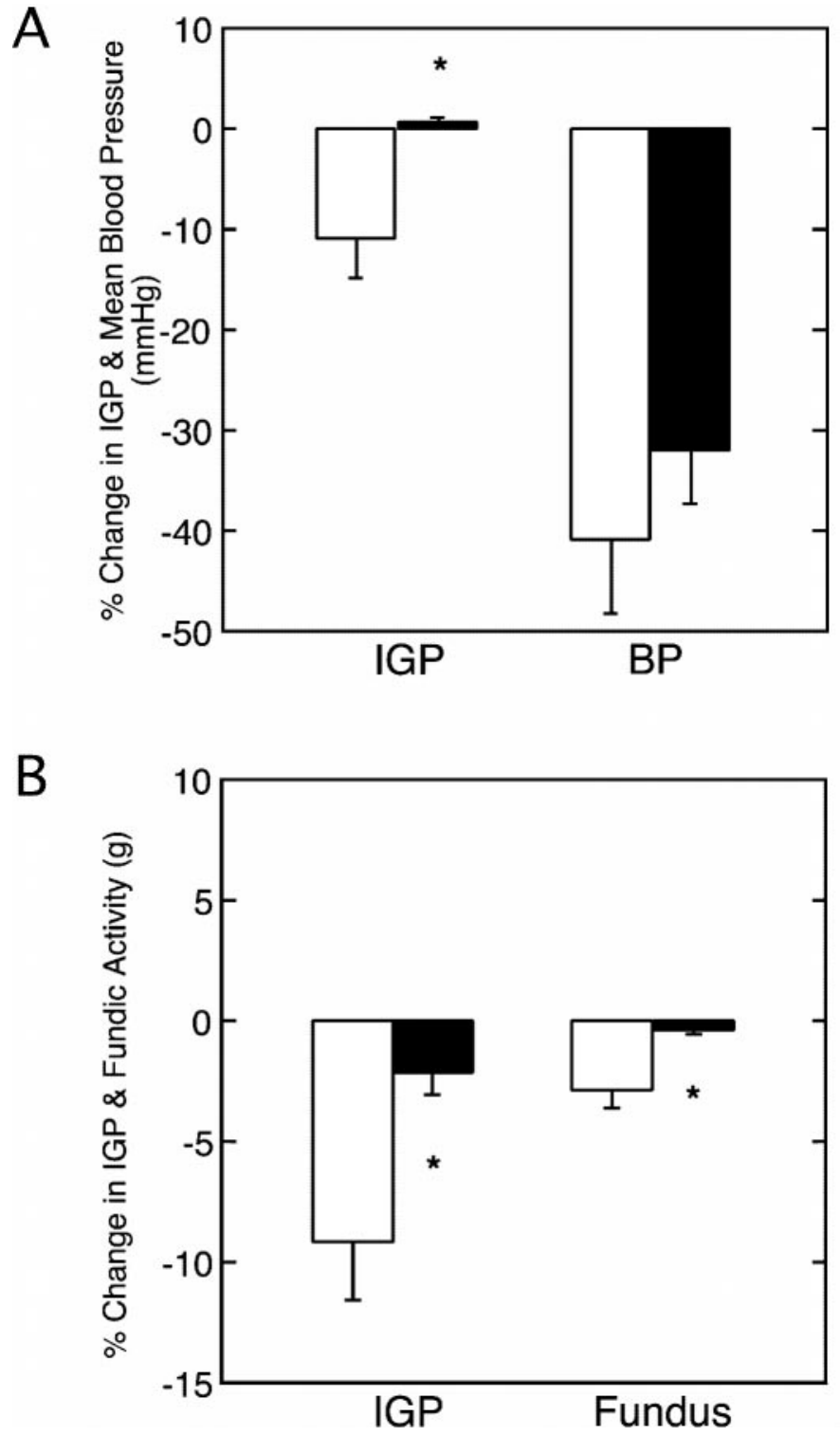

Figure 10. Effects of kynurenic acid on microinjected $(A)$ or intravenous $(B)$ nicotine-induced changes in intragastric pressure $(I G P)(A, B)$, blood pressure $(A)$, and fundic contractions $(B)$. $A$ shows the effects of nicotine $(10 \mathrm{pmol} / 60 \mathrm{nl})$ microinjected unilaterally into the mNTS on IGP and BP, before (white histograms) and after (black histograms) $100 \mathrm{pmol} / 60 \mathrm{nl}$ of kynurenic acid microinjected into the same site $(n=7)$. $B$ shows two groups of animals. One group was treated with saline microinjected bilaterally into the mNTS (white histograms; $n=4$ ), and the other was treated with kynurenic acid $(100 \mathrm{pmol} / 60 \mathrm{nl})$ microinjected bilaterally into the mNTS (black histograms; $n=6$ ). ${ }^{*} p<0.05$ as compared with initial nicotine response $(A)$ or as compared with the saline-treated group $(B)$, using paired and unpaired Student's $t$ tests, respectively.

nicotine-induced effects at the mNTS, experiments were performed wherein we microinjected the NOS inhibitor, L-NAME, $45 \mathrm{nmol} / 60 \mathrm{nl}$, bilaterally into the mNTS. In these experiments, nicotine was first microinjected unilaterally $(10 \mathrm{pmol} / 60 \mathrm{nl})$ into the mNTS, and this was repeated 15-20 min after treatment with L-NAME. The data that we obtained are tabulated in Table 7, and they indicate that bilateral microinjection of L-NAME into the mNTS significantly counteracted the effects of nicotine to decrease IGP and reduce tonic contractions of the fundus. It 


\begin{tabular}{|c|c|c|c|c|c|}
\hline \multirow{2}{*}{$\begin{array}{l}\text { Dose of nicotine } \\
(\mathrm{pmol} / 60 \mathrm{nl})\end{array}$} & \multirow[b]{2}{*}{ Pretreatment } & \multicolumn{4}{|c|}{ Effects of nicotine on } \\
\hline & & IGP & Fundus & aMMI & $\mathrm{BP}$ \\
\hline \multirow[t]{3}{*}{10} & None & $-14.9 \pm 2.6 \%$ & $-3.2 \pm 0.7$ & $-11.0 \pm 3.3$ & $-29.8 \pm 3.1$ \\
\hline & L-NAME (mNTS) & $-3.1 \pm 0.9 \%^{a}$ & $-0.7 \pm 0.2^{a}$ & $-14.2 \pm 2.6$ & $-31.2 \pm 5.3$ \\
\hline & L-ARG (mNTS) & $-20.8 \pm 4.5 \%^{a}$ & $-4.0 \pm 1.0^{a}$ & $-13.6 \pm 3.4$ & $-35.6 \pm 4.8$ \\
\hline \multirow[t]{2}{*}{10} & None & $-13.6 \pm 3.1 \%$ & $-2.9 \pm 0.7$ & $-13.4 \pm 2.0$ & $-26.4 \pm 2.3$ \\
\hline & L-NAME (DMV) & $-14.9 \pm 2.3 \%$ & $-2.5 \pm 0.4$ & $-12.9 \pm 3.4$ & $-28.7 \pm 3.9$ \\
\hline
\end{tabular}

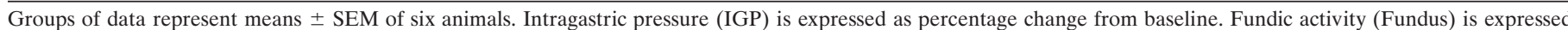

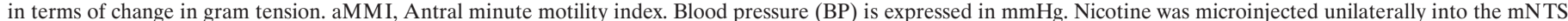

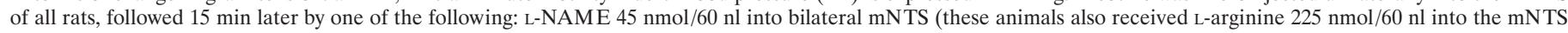
bilaterally) or L-NAME $45 \mathrm{nmol} / 60 \mathrm{nl}$ into bilateral DMV. Nicotine was microinjected again unilaterally 15-20 min after treatment.

${ }^{a} p<0.05$ using ANOVA followed by Duncan's, compared with controls.

should be noted that when L-NAME was microinjected unilaterally into the mNTS at the same site as nicotine, there was no reduction in nicotine-induced effects on IGP and fundus (data not shown). L-NAME treatment had no effect on nicotineinduced decreases in either the phasic contractions of the antrum or the mean arterial blood pressure (Table 7). Furthermore, parallel studies with L-NAME and nicotine were performed at the DMV. In this case, L-NAME microinjected bilaterally had no effect on nicotine-induced decreases in IGP, fundus tonic contractions, antrum phasic contractions, and mean arterial blood pressure (Table 7). A precursor of nitric oxide, L-arginine, was microinjected into the mNTS (bilaterally) of some animals that were treated with L-NAME. This was performed to show the reversibility of the nitric oxide-mediated, nicotine-induced effects from the mNTS. As shown in Table 7, L-arginine restored the nicotine-induced decrease in IGP and fundus tone. When L-NAME was microinjected bilaterally into the mNTS, there was an increase in IGP ( $9 \pm 1.5 \%$ change from baseline), antral motility $(12.9 \pm 4.0, \mathrm{aMMI})$, and fundus activity $(1.1 \pm 0.4 \mathrm{gm}$ change from baseline). The endpoints recorded had returned to baseline within $10 \mathrm{~min}$ before the next microinjection of nicotine. In four of six animals, the blood pressure dropped $(99.4 \pm 7.3$ to $79.2 \pm 5.1 \mathrm{mmHg}$ ) and respiratory depression occurred. These animals were mechanically ventilated and endpoints returned to baseline within $10 \mathrm{~min}$. When L-arginine was microinjected into the mNTS unilaterally or bilaterally, a decrease in IGP $(-22.1 \pm$ $6.5 \%$ change from baseline), antral motility $(-19.2 \pm 4.7$, aMMI), and fundus contractility $(-2.3 \pm 0.4 \mathrm{gm}$ change from baseline) occurred. These endpoints returned to baseline within $10-15$ min.

On the basis of positive data obtained using bilateral cervical vagotomy described previously (Table 3 and related text), it is clear that events initiated by nicotine acting at the mNTS must be communicated to the DMV to exert its effects on IGP. Interneurons and neurotransmitters implicated in communicating information between these nuclei, in addition to NO, include GABAergic (McCann and Rogers, 1994), glutamatergic (McCann and Rogers, 1994), and noradrenergic (Fukuda et al., 1987) systems. To investigate the possible role of each, we used pharmacologic agents microinjected bilaterally into the DMV and measured gastric mechanical and blood pressure changes evoked by microinjecting nicotine unilaterally into the mNTS. Data obtained are summarized in Figure 11 and indicate that blockade of GABA receptors at the DMV with bicuculline (50 pmol/60 nl per site) does not counteract nicotine-induced decreases in IGP (or mean arterial blood pressure). Bicuculline microinjection, however, did counteract nicotine-induced decreases in phasic contractions recorded from the antrum (Fig. 11). Kynurenic acid in a dose effective at the mNTS (Fig. 10) also had no effect on nicotine-induced decreases in IGP (Fig. 11). Likewise, kynurenic acid microinjected into the DMV did not counteract either the decrease in antral contractions or the decrease in blood pressure produced by nicotine microinjected into the mNTS (Fig. 11). In contrast, blockade of $\alpha 2$ adrenergic receptors at the DMV with yohimbine significantly counteracted nicotine-induced decreases in IGP and fundus tonic contractions (Fig. 11). Yohimbine did not alter the decreases in antral phasic contractions and the mean arterial blood pressure produced by nicotine microinjected into the mNTS (Fig. 11).

Two experiments were performed using another $\alpha 2$ receptor antagonist, SKF 86466. This agent was used in the same way as yohimbine except that the doses of SKF were lower (100 vs 500 pmol for yohimbine). In the first animal studied, nicotine, 10 pmol, was microinjected unilaterally into the mNTS and produced a $12.4 \%$ decrease in IGP and a $32.4 \mathrm{mmHg}$ decrease in mean blood pressure. SKF was then microinjected bilaterally into the DMV, and nicotine microinjections were repeated in the mNTS. Now nicotine evoked only a $5.2 \%$ decrease in IGP, whereas the nicotine-induced decrease in mean blood pressure was unaffected $(-29.9 \mathrm{mmHg})$. Corresponding data for nicotineinduced changes in IGP and mean blood pressure from the mNTS before SFK treatment of the DMV in the second experiment were $-10.0 \%$ and $-26.8 \mathrm{mmHg}$, respectively. After SKF 86466 was microinjected bilaterally into the DMV, nicotineinduced effects from the mNTS on IGP and mean blood pressure were $-4.8 \%$ and $-28.4 \mathrm{mmHg}$, respectively.

Kynurenic acid had no significant effects per se on either gastric endpoints or mean arterial blood pressure after microinjections unilaterally or bilaterally into the DMV. When bicuculline was microinjected unilaterally or bilaterally into the DMV (data calculated after bilateral injections, although effect was seen with unilateral injections), there was an increase in IGP ( $4 \pm 0.9 \%$ change from baseline), antral motility (29.4 \pm 7.3 , aMMI), and fundus activity (1.4 \pm 0.8 gm change from baseline) $(n=6)$. When yohimbine was microinjected bilaterally into the DMV, there were usually two responses seen. Either there was an increase in IGP $(5.8 \pm 0.7 \%$ change from baseline), antral motility $(15.2 \pm 7.8, \mathrm{aMMI})$, and fundus activity $(1.9 \pm 0.8 \mathrm{gm}$ change from baseline) $(n=3)$ or there was no effect on the baseline activity $(n=2)$. In both cases, there was no difference in 

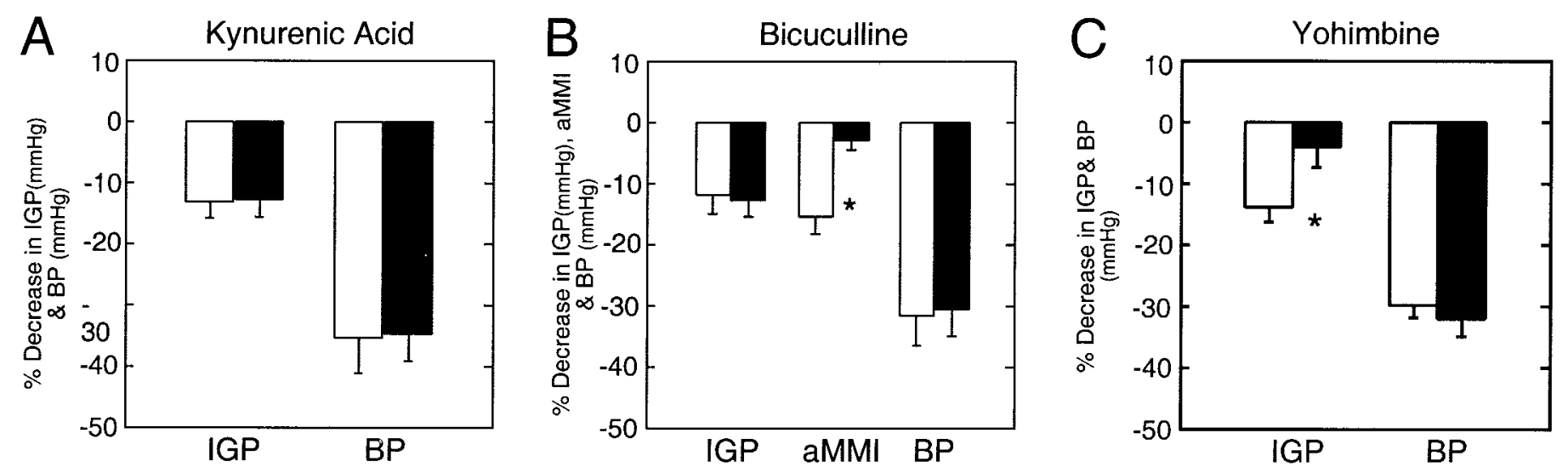

Figure 11. Nicotine-induced decreases in intragastric pressure $(I G P)$ from the mNTS is mediated by norepinephrine released onto $\alpha 2$ adrenoreceptors at the DMV, and the decrease in aMMI is mediated by GABA release onto GABA receptors at the DMV. Nicotine $(10 \mathrm{pmol} / 60 \mathrm{nl})$ was microinjected into the mNTS unilaterally (white histograms) followed by the administration of kynurenic acid (100 pmol/60 nl) $(A)$, bicuculline $(25 \mathrm{pmol} / 60 \mathrm{nl})(B)$, or yohimbine $(500 \mathrm{pmol} / 60 \mathrm{nl})(C)$ bilaterally into the DMV 15 min later. Five minutes after microinjection of the antagonists, nicotine was reinjected into the same site in the mNTS (black histograms). Each set of data represents the mean \pm SEM of the responses of four to seven animals. * $p<0.05$ as compared with pre-antagonist responses, with a paired Student's $t$ test.

the amount of blockade of nicotine-induced responses. The same effect was seen with SKF 86466. In one animal there was an increase in IGP (8.1\% change from baseline), antral motility (9.4, aMMI), and fundus activity (1.1 gm change from baseline) or there was no effect on the baseline activity $(n=1)$. In the cases of all antagonists, the endpoints recorded had returned to baseline within $10 \mathrm{~min}$ before the next microinjection of nicotine.

\section{Studies to determine what efferent pathways emanating from the DMV are affected by nicotine}

In general there appear to be at least three types of efferent pathways emanating from the DMV that can influence mechanical behavior of the stomach. The conventional pathway comprises cholinergic motor neurons in the DMV that synapse onto postganglionic cholinergic neurons. Inhibition of this pathway should inhibit gastric contractility. Another pathway comprises cholinergic motor neurons in the DMV that synapse onto nitriergic neurons in the stomach (Berthoud, 1995). Activation of this pathway should also inhibit gastric contractility. A less conventional pathway comprises nitriergic motor neurons in the DMV, the activation of which inhibits gastric contractility (Krowicki et al., 1997, 1999). The ganglionic blocker, hexamethonium, administered systemically should block the first two pathways but have no effect on the third pathway (Krowicki et al., 1999). The DMV c-Fos data obtained with i.v. nicotine do not support activation of any DMV neurons, thus suggesting no involvement of pathways two and three. To further rule out the third pathway, we performed experiments wherein hexamethonium $10 \mathrm{mg} / \mathrm{kg}$ was given intravenously, and nicotine-induced responses from the mNTS were assessed. Data obtained are summarized in Figure 12 and indicate that hexamethonium blocked the effects of nicotine on IGP. As mentioned earlier (in Materials and Methods), saline was given intravenously to counteract the hypotension that occurred with hexamethonium [baseline blood pressure, $95 \pm 11 \mathrm{mmHg}$; after saline, $99 \pm 8 \mathrm{mmHg}$; after hexamethonium, $53 \pm 7 \mathrm{mmHg}$ $(n=4)$ ]. Also, phasic activity ceased to exist after the administration of hexamethonium. Blockade of nicotine-induced responses was not caused by loss of all tone in the stomach muscu-

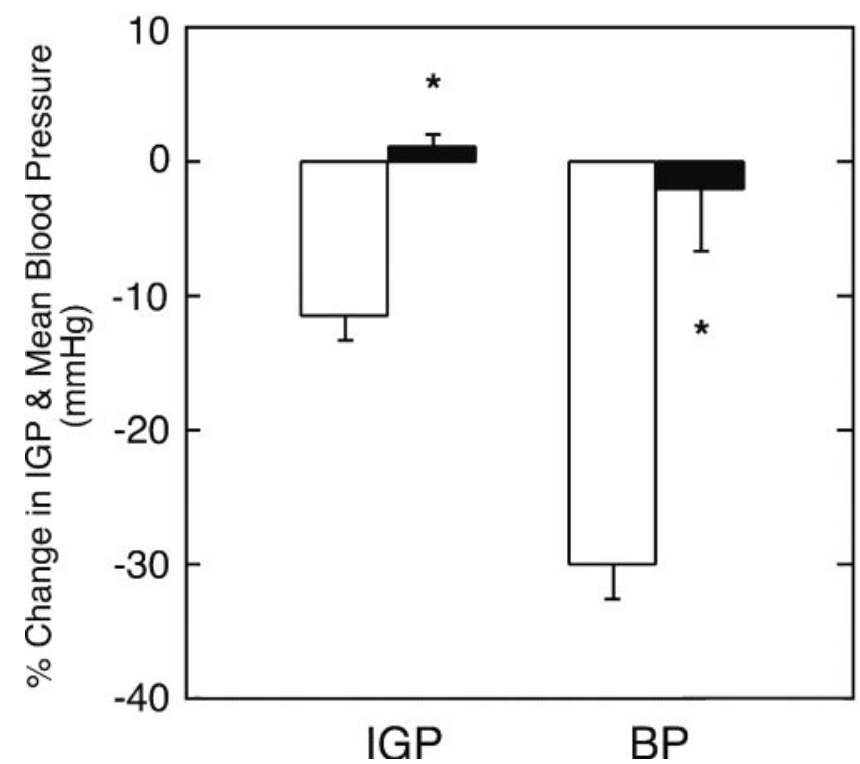

Figure 12. Effects of i.v. hexamethonium $(10 \mathrm{mg} / \mathrm{kg})$ on microinjected nicotine-induced $(10 \mathrm{pmol} / 60 \mathrm{nl})$ changes in intragastric pressure $(I G P)$ and blood pressure $(B P)$. Hexamethonium was given $15 \mathrm{~min}$ after the unilateral microinjection of nicotine into the mNTS (white histograms). Nicotine was reinjected 5-10 min after hexamethonium was given (black histograms). Data represent the mean \pm SEM of the responses of four animals. ${ }^{*} p<0.05$ by paired Student's $t$ test as compared with prehexamethonium effects.

lature, because after hexamethonium was administered, IGP remained at baseline levels.

\section{DISCUSSION}

We propose that nicotine given intravenously in low doses decreases fundus tonic contractions and IGP by activating the circuitry shown in Figure 13. We suggest that this circuitry is 


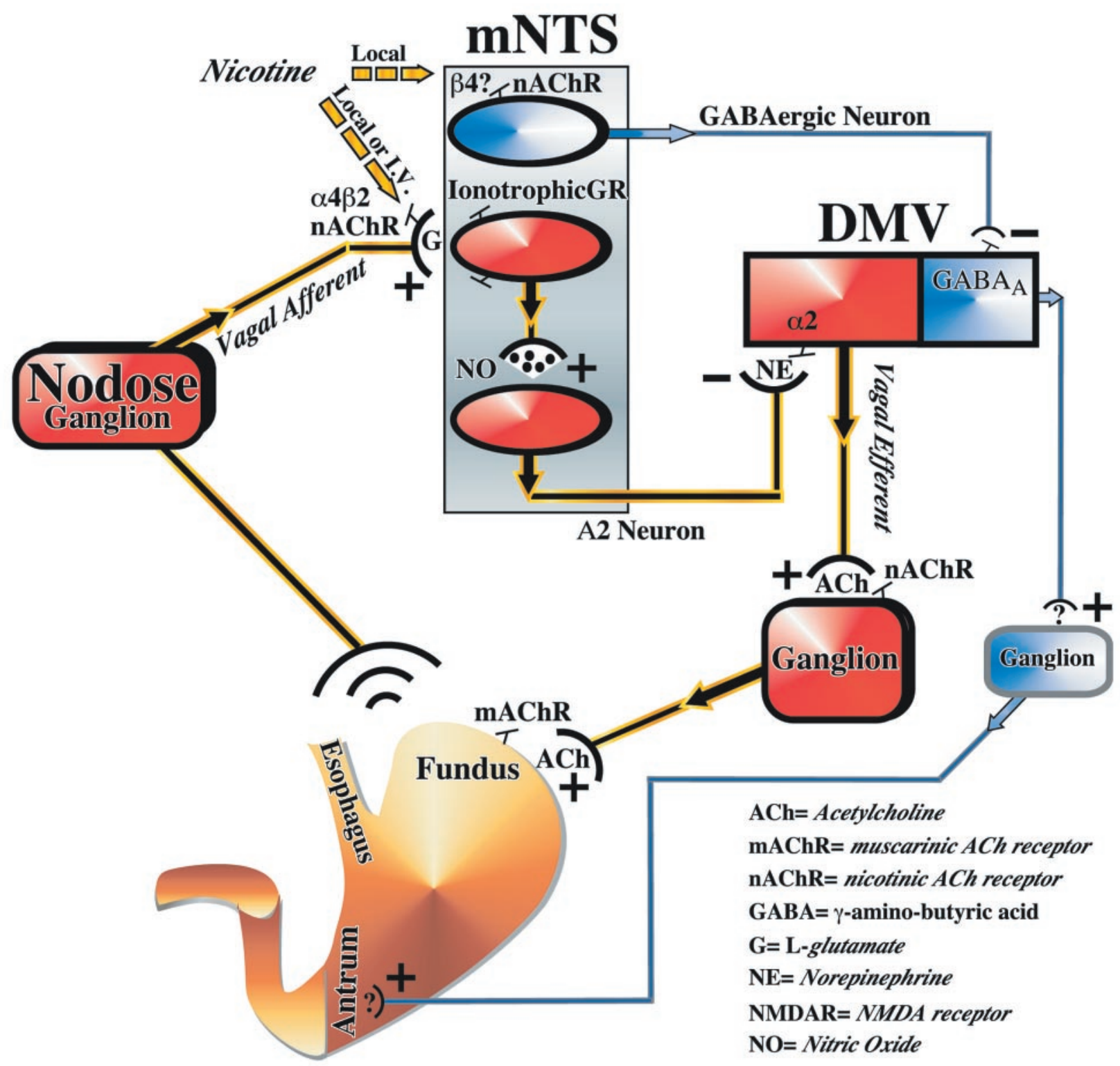

Figure 13. Schematic of proposed neurocircuitry involved in nicotine-induced effects on intragastric pressure and phasic contractions in the dorsal medulla.

synonymous with the vago-vagal reflex pathway (Rogers et al., 1995). This reflex can be activated by mechanoreceptors in the stomach with subsequent excitation of vagal afferent neurons that project into the mNTS (Rogers et al., 1995). Glutamate is released (McCann and Rogers, 1994) and activates ionotropic receptors on second-order NTS neurons. We propose that the second-order NTS neurons are nitriergic, based in part on data of Ruggiero and colleagues (1996), who used diaphorase activity of NO synthase as a marker of these neurons and describe a well circumscribed cell cluster within the mNTS. In addition, Lin and colleagues (2000) report an anatomical link between glutamatergic and nitriergic neurons in the NTS. Furthermore, all neuronal NOS immunoreactive neurons in the NTS contain NMDAR1 immunoreactivity (Lin and Talman, 2000). We suggest that the second-order nitriergic interneurons are contained within the
mNTS and activate mNTS-A2 projection neurons to the DMV. Evidence that A2 neurons connect the mNTS to the DMV has been documented by several investigators (Pickel et al., 1986; Fukuda et al., 1987; Siaud et al., 1989; Bertolino et al., 1997). Norepinephrine released from A2 neurons within the DMV has been shown to activate postsynaptic $\alpha 2$ receptors and result in inhibition of DMV neurons (Fukuda et al., 1987).

The site where i.v. nicotine acts within the circuit depicted in Figure 13 is the mNTS, specifically $\alpha 4 \beta 2$ receptors located on vagal afferent nerve terminals. Evidence for this is as follows. (1) Microinjection of nicotine into the mNTS mimics the effects seen with i.v. low doses of nicotine; IGP decreases elicited from mNTS, like those observed intravenously, were blocked by bilateral cervical vagotomy; and hexamethonium microinjected bilaterally into the mNTS blocked both microinjected (Ferreira et al., 2001) 
and intravenously administered nicotine on IGP. (2) A presynaptic excitatory effect in the mNTS resulting in glutamate release was shown using the glutamate antagonist kynurenic acid. This specific blocking agent for glutamate on ionotropic receptors (Jackson et al., 1985; Soltis and DiMicco, 1991) microinjected into the mNTS blocked both microinjected and low dose i.v. nicotine. (3) The nAChR located presynaptically in the mNTS, presumably on afferent vagal nerve terminals, appears to be an $\alpha 4 \beta 2$ subtype, based on our finding that DHBE, an agent with relative selectivity for blocking $\mathrm{nAChRs}$ with $\beta 2$ subunits (Harvey and Luetje, 1996), counteracted the IGP-decreasing effect of nicotine either microinjected into the mNTS or administered intravenously in a low dose. The data obtained with microinjected cytisine into the mNTS were additional evidence for the presence of a $\beta 2$ subunit. Cytisine is relatively inactive on nAChRs containing a $\beta 2$ subunit (Luetje and Patrick, 1991) and was ineffective in lowering the IGP after microinjection into the mNTS. The $\beta 2$ subunit has been detected by immunohistochemistry in the NTS and may be on axon terminals (Swanson et al., 1987). It could be argued that we may be dealing with an $\alpha 3 \beta 2 \mathrm{nAChR}$ subtype instead of an $\alpha 4 \beta 2 \mathrm{nAChR}$ subtype. However, nicotine is relatively inactive on the $\alpha 3 \beta 2 \mathrm{nAChR}$ subtype (Luetje and Patrick, 1991), which would be inconsistent with our observation that nicotine was effective in lowering IGP and fundus tonic contractions after microinjection into the mNTS.

The release of glutamate by nicotine engages the nitriergic-A2 pathway depicted in Figure 13. Evidence for this was that microinjection of a NOS inhibitor, L-NAME, bilaterally into the mNTS counteracted the effects of nicotine microinjected into the mNTS on IGP. Parallel experiments performed with L-NAME microinjected into the DMV had no effect. Furthermore, yohimbine, a drug that blocks the inhibitory effect of norepinephrine on $\alpha 2$ adrenoreceptors on DMV neurons (Fukuda et al., 1987), microinjected into the DMV also blocked nicotine-evoked decreases in IGP elicited from the mNTS. Parallel experiments performed with yohimbine microinjected into the mNTS had no effect. Identical results were obtained with another agent known to selectively block $\alpha 2$-adrenoreceptors, namely, SKF 86466 (Hieble et al., 1986). Systemically administered nicotine in the same dose range used in our study activates A2 neurons (Valentine et al., 1996).

The efferent projecting pathway out of the DMV affected by nicotine appeared to be one that involves inhibition of vagal preganglionic parasympathetic neurons synapsing onto cholinergic postganglionic parasympathetic neurons innervating fundus smooth muscle (Fig. 13). Evidence for this is the lack of any direct excitation by nicotine on peripherally projecting DMV neurons based on our c-Fos data. Furthermore, i.v. hexamethonium, a quaternary ganglionic blocking agent that does not cross the blood-brain barrier, blocked microinjected nicotine-induced decreases in IGP and tonic contractions of the fundus. The circuitry, nAChR location, and subtype described in Figure 13 for nicotineinduced changes in gastric function contrasts with the pathways excited by microinjected nicotine into the mNTS leading to inhibition of antral motility. This circuitry (Fig. 13) probably involves activation of a postganglionic nAChR subtype in the mNTS containing a $\beta 4$ subunit (based on the positive finding with cytisine) and activation of a GABAergic interneuron (based on the ability of microinjected bicuculline into the DMV to block the response). The circuitry in Figure 13 also contrasts with vago- vagal pathways described by others (McCann and Rogers, 1994; Rogers et al., 1999), in which drugs that block noradrenergic $\alpha 2$ receptors were found to be ineffective (McCann and Rogers, 1994) and where vago-vagal pathways involved activation of a vagal efferent inhibitory pathway (Rogers et al., 1999). Iontophoretic application of norepinephrine to a DMV neuron that was inhibited by gastric distension was also inhibited by norepinephrine (McCann and Rogers, 1994), and this result is consistent with our proposed scheme (Fig. 13). However, a drug known to block $\alpha 2$ adrenoreceptors (as well as imidazoline receptors), idazoxan, was tested and did not inhibit distension-induced inhibition of DMV neuron firing rates. We did not test idazoxan because of its effect to block not only $\alpha 2$ adrenoreceptors but imidazoline receptors (Ernsberger et al., 1990). Instead, we tested the $\alpha 2$ adrenoreceptor antagonists yohimbine and SKF 86466, which are more selective in blocking $\alpha 2$ adrenoreceptors. We found that both were effective in blocking nicotine-induced decreases in gastric tone. Rogers and colleagues (1999) studied a vagal efferent inhibitory pathway that appeared to be excited from the subnucleus pars centralis of the NTS. The part of the NTS that was activated in our study was primarily the mNTS.

Our data with microinjected nicotine into the mNTS evoking dose-related effects on the fundus (gastric tone) and the antrum (phasic contractions) raise the possibility that the function of the stomach can be regulated by separate neural pathways. A low dose of nicotine microinjected into the mNTS affects the gastric tone, whereas a higher dose is required for evoking effects on phasic contractions (Fig. 6). Nicotine-induced decreases in gastric tone engaged a circuit (Fig. 13) that used norepinephrine at $\alpha 2$ adrenoreceptors at the DMV, whereas the nicotine-induced decreases in phasic contractions engaged a circuit (Fig. 13) that used GABA at the DMV. A separation of pathways was evident when bicuculline was tested on nicotine-induced decreases in gastric tone and phasic contractions and was found to block only the inhibition of phasic contractions. These data raise the interesting question of whether physiological (or pathological) stimuli that activate the vago-vagal reflex leading to changes in gastric pressure use norepinephrine as a CNS neurotransmitter, whereas such stimuli that activate the vago-vagal reflex leading to changes in phasic contractions use GABA as a neurotransmitter. Confirmation of our finding that neural pathways regulate gastric tone and phasic contractions can be found in the results published by Talman and colleagues (1991). These investigators reported that cholecystokinin microinjected into the NTS of rats can decrease tonic gastric pressure and eliminate phasic gastric contractions. In some experiments, a decrease in tonic pressure occurred without significant changes in phasic contractions. The authors suggested that there was an independence of tonic and phasic contractions of the stomach.

Finally, our data with high i.v. doses of nicotine suggested that the effects on antral phasic contractions and arterial blood pressure were mediated through activation of the sympathetic nervous system. Evidence for this is that bilateral cervical vagotomy did not alter the responses and the findings of others indicating that both the inhibition of the antrum and the rise in arterial blood pressure are blocked by peripherally administered adrenergic receptor antagonists (Carlson et al., 1970a,b).

Our data represent the first example in which the CNS circuitry and CNS nAChR subtypes have been elucidated for an effect of i.v. nicotine. Events are initiated by nicotine acting at vagal 
afferent terminals in the mNTS to excite an $\alpha 4 \beta 2 \mathrm{nAChR}$. Excitation leads to release of glutamate and NO-mediated excitation of a noradrenergic interneuron that projects to the DMV. Norepinephrine then inhibits tonically active DMV neurons projecting to the fundus. Not only is this circuitry supported by multiple experiments using different methodologies, it is also in agreement with most previous studies that have examined individual aspects of these neural pathways. Thus, we feel that the scheme represented in Figure 13 represents the major pathway by which systemic nicotine evokes its effects to inhibit gastric fundus tonic contractions and delay gastric emptying (Nowak et al., 1987). A similar pathway has been proposed as providing satiety signaling (Schwartz et al., 2000), and we speculate that the ability of smoking to reduce appetite (Blaha et al., 1998) might be attributable to activation of this circuitry.

\section{REFERENCES}

Barnett CW (1927) Tobacco smoking as a factor in the production of peptic ulcer and gastric neurosis. Boston Med Surg J 197:457-459.

Beltran B, Barrachina MD, Mendez A, Quintero E, Esplugues JV (1999) Synthesis of nitric oxide in the dorsal motor nucleus of the vagus mediates the inhibition of gastric acid secretion by central bombesin. Br J Pharmacol 127:1603-1610.

Berthoud HR (1995) Anatomical demonstration of vagal input to nicotinamide acetamide dinucleotide phosphate diaphorase-positive (nitrergic) neurons in rat fundic stomach. J Comp Neurol 358:428-439.

Bertolino M, Vicini S, Gillis R, Travagli A (1997) Presynaptic alpha2adrenoceptors inhibit excitatory synaptic transmission in rat brain stem. Am J Physiol 272:G654-661.

Blaha V, Yang ZJ, Meguid M, Chai JK, Zadak Z (1998) Systemic nicotine administration suppresses food intake via reduced meal sizes in both male and female rats. Acta Medica (Hradec Kralove) 41:167-173.

Carlson GM, Ruddon RW, Hug Jr CC, Bass P (1970a) Effects of nicotine on gastric antral and duodenal contractile activity in the dog. J Pharmacol Exp Ther 172:367-376.

Carlson GM, Ruddon RW, Hug Jr CC, Schmiege SK, Bass P (1970b) Analysis of the site of nicotine action on gastric antral and duodenal contractile activity. J Pharmacol Exp Ther 172:377-383.

Colquhoun LM, Patrick JW (1997) Pharmacology of neuronal nicotinic acetylcholine receptor subtypes. Adv Pharmacol 39:191-220.

DeLean A, Munson PJ, Rodbard D (1987) Simultaneous analysis of families of sigmoidal curves: application to bioassay, and physiological dose-response curves. Am J Physiol 235:E97-E102.

Doxey JC, Lane AC, Roach AG, Virdee NK (1984) Comparison of the alpha-adrenoceptor antagonist profiles of idazoxan (RX 781094), yohimbine, rauwolscine and corynanthine. Naunyn Schmiedebergs Arch Pharmacol 325:136-144.

Ernsberger P, Giuliano R, Willette RN, Reis DJ (1990) Role of imidazole receptors in the vasodepressor response to clonidine analogs in the rostral ventrolateral medulla. J Pharmacol Exp Ther 253:408-418.

Ferreira M, Singh A, Dretchen KL, Kellar KJ, Gillis RA (2000) Brainstem nicotinic receptor subtypes that influence intragastric and arterial blood pressures. J Pharmacol Exp Ther 294:230-238.

Ferreira M, Ebert SN, Perry DC, Yasuda RP, Baker CM, Davila-Garcia MI, Kellar KJ, Gillis RA (2001) Evidence of a functional alpha7neuronal nicotinic receptor subtype located on motoneurons of the dorsal motor nucleus of the vagus. J Pharmacol Exp Ther 296:260-269.

Fukuda A, Minami T, Nabekura J, Oomura Y (1987) The effects of noradrenaline on neurones in the rat dorsal motor nucleus of the vagus, in vitro. J Physiol (Lond) 393:213-231.

Gomez RE, Ernsberger P, Feinland G, Reis DJ (1991) Rilmenidine lowers arterial pressure via imidazole receptors in brainstem $\mathrm{C} 1$ area. Eur J Pharmacol 195:181-191.

Harvey SC, Luetje CW (1996) Determinants of competitive antagonist sensitivity on neuronal nicotinic receptor $\beta$ subunits. J Neurosci 16:3798-3806.

Hieble JP, DeMarinis RM, Fowler PJ, Matthews WD (1986) Selective alpha-2 adrenoceptor blockade by SK\&F 86466: in vitro characterization of receptor selectivity. J Pharmacol Exp Ther 236:90-96.

Humphreys GA, Davison JS, Veale WL (1992) Hypothalamic neuropeptide $\mathrm{Y}$ inhibits gastric acid output in rat: role of the autonomic nervous system. Am J Physiol 263:G726-732.

Jackson H, Nemeth EF, Parks TN (1985) Non- $N$-methyl-D-aspartate receptors mediating synaptic transmission in the avian cochlear nucleus: effects of kynurenic acid, dipicolinic acid and streptomycin. Neuroscience 16:171-179.

Kohagen KR, Kim MS, McDonnell WM, Chey WD, Owyang C, Hasler WL (1996) Nicotine effects on prostaglandin-dependent gastric slow wave rhythmicity and antral motility in nonsmokers and smokers. Gastroenterology 110:3-11.

Krowicki ZK, Hornby PJ (1993) Serotonin microinjected into the nucleus raphe obscurus increases intragastric pressure in the rat via a vagally mediated pathway. J Pharmacol Exp Ther 265:468-476.

Krowicki ZK, Sharkey KA, Serron SC, Nathan NA, Hornby PJ (1997) Distribution of nitric oxide synthase in rat dorsal vagal complex and effects of microinjection of nitric oxide compounds upon gastric motor function. J Comp Neurol 377:49-69.

Krowicki ZK, Sivarao DV, Abrahams TP, Hornby PJ (1999) Excitation of dorsal motor vagal neurons evokes non-nicotinic receptor-mediated gastric relaxation. J Auton Nerv Syst 77:83-89.

Lin LH, Talman WT (2000) $N$-methyl-D-aspartate receptors on neurons that synthesize nitric oxide in rat nucleus tractus solitarii. Neuroscience 100:581-588.

Lin LH, Emson PC, Talman WT (2000) Apposition of neuronal elements containing nitric oxide synthase and glutamate in the nucleus tractus solitarii of rat: a confocal microscopic analysis. Neuroscience 96:341-350.

Luetje CW, Patrick J (1991) Both $\alpha$ and $\beta$ subunits contribute to the agonist sensitivity of neuronal nicotinic acetylcholine receptors. J Neurosci 11:837-845.

McCann MJ, Rogers RC (1994) Functional and chemical anatomy of a gastric vago-vagal reflex, Chap 6. In: Innervation of the gut, pathophysiological implications (Tache Y, Wingate DL, Burks TF, eds), pp 81-92. Boca Raton, FL: CRC.

McDonnell WM, Owyang C (1989) Smoking markedly inhibits gastric motility in smokers and non-smokers. Gastroenterology 96:A332.

McGehee DS, Role LW (1995) Physiological diversity of nicotinic acetylcholine receptors expressed by vertebrate neurons. Annu Rev Physiol 57:521-546.

Nagata M, Osumi Y (1990) Central inhibition of gastric motility by intravenously administered nicotine in rats. Jpn J Pharmacol 52:397-403.

Nagata M, Osumi Y (1991) Involvement of nicotinic receptors in the dorsal motor nucleus of the vagus in regulation of gastric motility in rats. Jpn J Pharmacol 56:539-542.

Nagata M, Okuma Y, Osumi Y (1986) Nicotine applied into the dorsal motor nucleus of the vagus inhibits enhanced gastric acid output and mucosal blood flow in rats. Eur J Pharmacol 121:313-318.

Nowak A, Jonderko K, Kaczor R, Nowak S, Skrzypek D (1987) Cigarette smoking delays gastric emptying of a radiolabeled solid food in healthy smokers. Scand J Gastroenterol 22:54-58.

Ormsbee III HS, Bass P (1976) Gastroduodenal motor gradients in the dog after pyloroplasty. Am J Physiol 230:389-397.

Panico WH, Cavuto NJ, Kallimanis G, Nguyen C, Armstrong DM, Benjamin SB, Gillis RA, Travagli RA (1995) Functional evidence for the presence of nitric oxide synthase in the dorsal motor nucleus of the vagus. Gastroenterology 109:1484-1491.

Paxinos G, Watson C (1998) The rat brain in stereotaxic coordinates. Sydney: Academic

Pickel VM, Chan J, Park DH, Joh TH, Milner TA (1986) Ultrastructural localization of phenylethanolamine $N$-methyltransferase in sensory and motor nuclei of the vagus nerve. J Neurosci Res 15:439-455.

Rinaman L, Verbalis JG, Stricker EM, Hoffman GE (1993) Distribution and neurochemical phenotypes of caudal medullary neurons activated to express c-Fos following peripheral administration of cholecystokinin. J Comp Neurol 338:475-490.

Roesch DM, Blackburn-Munro RE, Verbalis JG (2001) Mineralocorticoid treatment attenuates activation of oxytocinergic and vasopressinergic neurons by icv ANG II. Am J Physiol Regul Integrative Comp Physiol 280:R1853-R1864.

Rogers RC, McTigue DM, Hermann GE (1995) Vagovagal reflex control of digestion: afferent modulation by neural and "endoneurocrine" factors. Am J Physiol 268:G1-10.

Rogers RC, Hermann GE, Travagli RA (1999) Brainstem pathways responsible for oesophageal control of gastric motility and tone in the rat. J Physiol (Lond) 514:369-383.

Ruggiero DA, Mtui EP, Otake K, Anwar M (1996) Central and primary visceral afferents to nucleus tractus solitarii may generate nitric oxide as a membrane-permeant neuronal messenger. J Comp Neurol 364:51-67.

Schwartz MW, Woods SC, Porte Jr D, Seeley RJ, Baskin DG (2000) Central nervous system control of food intake. Nature 404:661-671.

Sesoko S, Muratani H, Yamazato M, Teruya H, Takishita S, Fukiyama K (1998) Contribution of alpha 2-adrenoceptors in caudal ventrolateral medulla to cardiovascular regulation in rat. Am J Physiol 274:R1119-1124.

Siaud P, Denoroy L, Assenmacher I, Alonso G (1989) Comparative 
immunocytochemical study of the catecholaminergic and peptidergic afferent innervation to the dorsal vagal complex in rat and guinea pig. J Comp Neurol 290:323-335

Soltis RP, DiMicco JA (1991) GABAA and excitatory amino acid receptors in dorsomedial hypothalamus and heart rate in rats. Am J Physiol 260:R13-20.

Sved AF, Tsukamoto K, Schreihofer AM (1992) Stimulation of alpha 2 -adrenergic receptors in nucleus tractus solitarius is required for the baroreceptor reflex. Brain Res 576:297-303.

Swanson LW, Simmons DM, Whiting PJ, Lindstrom J (1987) Immunohistochemical localization of neuronal nicotinic receptors in the rodent central nervous system. J Neurosci 7:3334-3342.

Talman WT, Perrone MH, Reis DJ (1980) Evidence for L-glutamate as the neurotransmitter of baroreceptor afferent nerve fibers. Science 209:813-815.

Talman WT, Andreasen K, Calvin J, Eversmann-Johanns S (1991) Cho- lecystokinin in nucleus tractus solitarii modulates tonic and phasic gastric pressure. Am J Physiol 261:R217-222.

Valentine JD, Matta SG, Sharp BM (1996) Nicotine-induced c-Fos expression in the hypothalamic paraventricular nucleus is dependent on brainstem effects: correlations with c-Fos in catecholaminergic and noncatecholaminergic neurons in the nucleus tractus solitarius. Endocrinology 137:622-630.

Verbalis JG, Stricker EM, Robinson AG, Hoffman GE (1991) Colecystokinin activates c-fos expression in hypothalamic oxytocin and corticotropin-releasing hormone neurons. J Neuroendocrinol 3:205-213.

Watson Jr RE, Wiegand SJ, Clough RW, Hoffman GE (1986) Use of cryoprotectant to maintain long-term peptide immunoreactivity and tissue morphology. Peptides 7:545.

Williford DJ, Ormsbee III HS, Norman W, Harmon JW, Garvey III TQ, DiMicco JA, Gillis RA (1981) Hindbrain GABA receptors influence parasympathetic outflow to the stomach. Science 214:193-194. 